\title{
Materials systems for interleave toughening in polymer composites
}

\author{
Nicola Vallack ${ }^{1, *}$ (I) and William W. Sampson ${ }^{1}$ \\ ${ }^{1}$ Department of Materials, University of Manchester, Manchester M13 9PL, UK
}

Received: 11 November 2021

Accepted: 4 February 2022

Published online:

8 March 2022

(C) The Author(s) 2022

\begin{abstract}
We review the literature describing the use of interleaves to increase interlaminar fracture toughness in fibre-reinforced polymer composites and hence to improve damage tolerance. From an analysis of data provided in the literature from the use of microfibre and nanofibre interleaves, we show that the performance of these widely researched systems is clearly differentiated when plotted against the mean coverage of the interleaf. Using a simple analysis, we suggest that this can be attributed to the influence of their porous architectures on the infusion of resin. We show also that the superior toughening performance of microfibre interleaves is only weakly influenced by the choice of fibre. We find also that the inclusion of carbon nanotubes within interleaves to deliver multifunctional composites can be optimised by using a hybrid system with microfibres.
\end{abstract}

Handling Editor: Joshua Tong.

Address correspondence to E-mail: nicola.vallack@manchester.ac.uk 


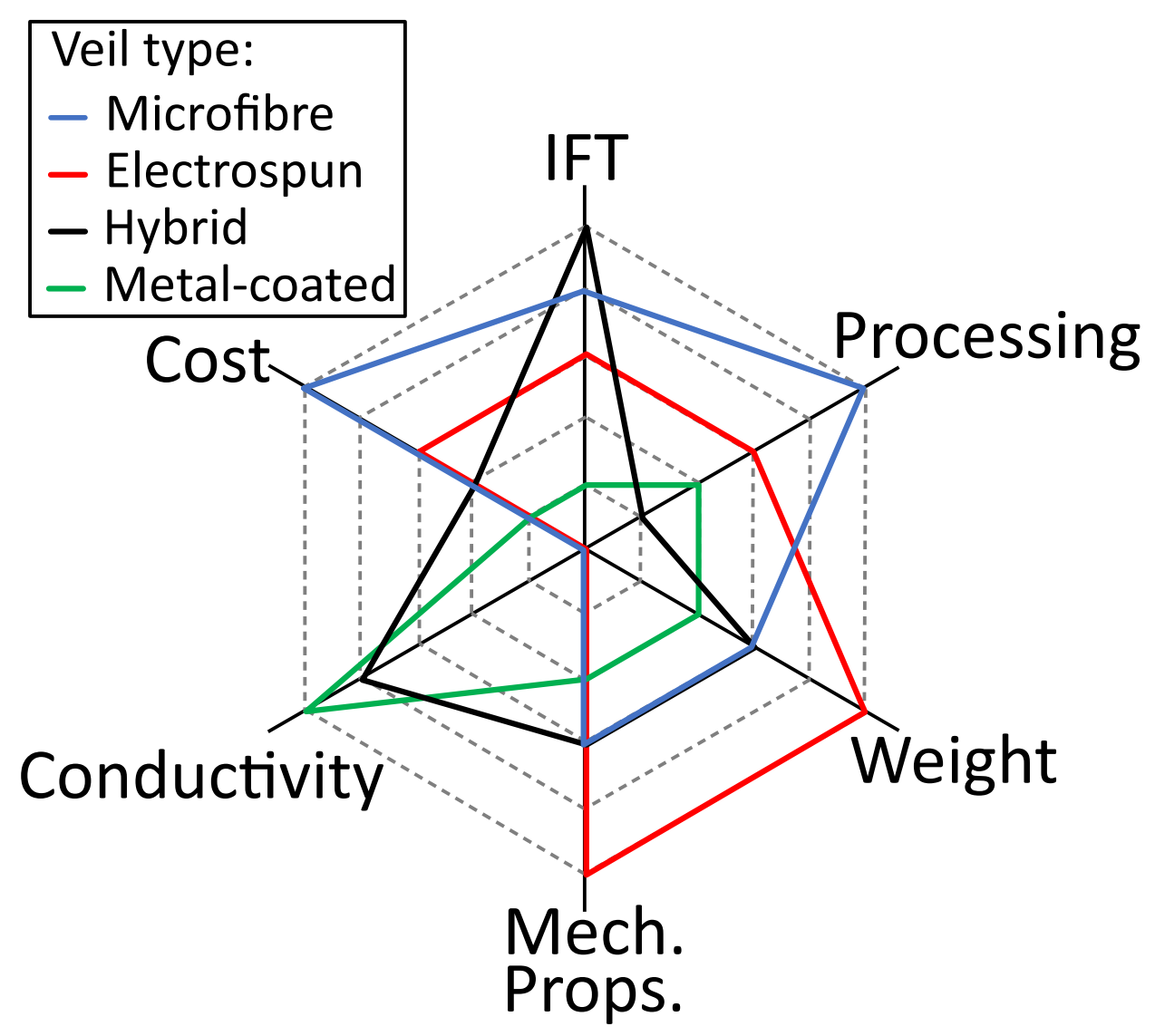

\section{Introduction}

Fibre-reinforced composite materials exhibit high strength and stiffness at relatively low weights and have rich potential to deliver multifunctionality, making them ideal for many high performance structural applications. As such, carbon fibre-reinforced polymers (CFRPs) are ubiquitous in modern aerospace structures and increasingly common in the automotive sector. Despite the desirable combination of physical properties exhibited by CFRPs, the polymer matrices used are typically rather brittle [1]. As such, they are susceptible to delamination from the build-up of stresses between plies, induced, for example, by an impact. There has been significant research over recent decades to identify technologies to improve the damage tolerance of laminated composites through methods such as matrix modification, interleaving with fibrous veils or polymer films, or structural through-thickness reinforcements. Improved damage tolerance is a priority for the aerospace industry, where composites are increasingly used for primary structures such as fuselage and wings. Inevitably, lighter aircraft yield better fuel efficiency, reducing both costs and air pollution [2].

Through-thickness reinforcements such as stitching, Z-pinning and 3D weaving are established pathways to increase damage tolerance, but they increase complexity of manufacture [3]. Improving mechanical performance by modifying the matrix material, e.g. using liquid rubber [4] or thermoplastics [5, 6], can lead to increased resin viscosity, impeding resin flow during resin transfer moulding 
(RTM) and vacuum-assisted resin infusion (VARI) [7].

Electrical conductivity of aircraft materials provides electromagnetic interference (EMI) shielding and lightning strike protection. This is currently achieved through addition of metal components, forming an 'electrical structure network', necessary for resilient function of aircraft systems [8]. Accordingly, there is a body of research addressing the need for such multifunctional composite materials that are lightweight, toughened and conductive without compromising other mechanical properties [9] and to reduce number of components required to meet performance specifications, maintaining weightsavings.

Interleaving is a technique in which an additional layer, such as a nonwoven polymer veil, or thermoplastic film is added between the laminae of reinforcing fibres within a composite [10]. Interleaves can reduce delamination through the bridging of cracks that occur along the matrix-rich interlaminar regions and by creating a more tortuous path for any crack to follow, dissipating more energy in the process [11]. Interleaves are used in the aerospace industry for a range of purposes, e.g. in metallic structures to improve acoustic damping and in CFRPs to inhibit fatigue crack propagation [10]. Nonwoven interleaves can be used within composite laminates to deliver electrical conductivity, EMI shielding, corrosion resistance, fracture toughness improvement, fire protection, as a surface carrier, as resin flow media or as a surface finish [12]. Interleaves can be inexpensive options for interlaminar toughening and are usually simple to incorporate within a composite lay-up. On the other hand, they add undesirable weight and thickness, and can reduce electrical conductivity. We note that film interleaves can impede resin flow during infusion if they are not sufficiently porous [13]. Naturally, if additional plies are added to the laminate for aerospace structures, then it is particularly important that their weight and thickness are minimised, since the main advantage of carbon fibre composites in aircraft is their strength-to-weight ratio and stiffness-to-weight ratio.

There is a considerable literature concerning the toughening of composite laminates, utilising many different methods, composite material systems, and testing methodologies; these reveal varying degrees of effectiveness. Several recent reviews consider options to improve the damage tolerance of fibre- reinforced composite materials. The review of Shrivastava and Singh [14] focusses on characterisation of fracture toughness of laminated composites and addresses fracture modes, the effect of matrix modifications and testing methodologies, highlighting examples of toughening with carbon nanotubes (CNTs). The review of Boon and Joshi [15] explores a range of methods to increase interlaminar fracture toughness (IFT), highlighting that some methods, such as through-thickness reinforcements, have an adverse effect on other properties of the composite e.g. in-plane mechanical performance. Dikshit et al. [16] also review IFT improvement techniques including matrix modification, fibre surface modification, 3D structures for interlaminar reinforcement, interleaving, and micro- and nano-fillers. A focus of that review is the use of CNTs, where the authors emphasise their potential in the aerospace industry. Shakil et al. [17] focus on epoxy matrix composites interleaved or reinforced using electrospun nanofibres, seeking to summarise the results from various structural loading regimes, where nanofibre features such as mechanical properties, aspect ratio, molecular chain alignment and pore size are linked to their ability to reinforce interlaminar regions. The review of Palazzetti and Zucchelli [18] examines the use of electrospun nanofibre interleaves for reinforcing composites, providing detailed comparison of literature studies and focussing on the different toughening mechanisms involved.

Here, we focus primarily on use of interleaves for interlaminar toughening of laminated composites with the specific objective to elucidate the understanding of differing reinforcement mechanisms of different materials systems. On this basis, we use this understanding to inform the choice of interleaves and to identify areas that are promising for future research. Whereas other reviews often provide a broad overview of composite toughening methods, or alternatively focus on one particular type of interleaf e.g. nanofibrous or CNTs, here, comparisons are made by bringing together insights from a range of interleaving material types. Interleaves have potential not only for significant improvements in fracture toughness, but are usually low cost and offer a diverse range of options from which many different materials systems can be tailored.

Interleaving has been researched for many years and shown to give significant improvements in damage tolerance. Despite the use of interleaving in 
aerospace structures, there remains significant potential to further develop interleaving systems, with a particular emphasis on increasing fracture toughness, and enabling multifunctionality. This review explores the challenges in translating promising fundamental research to the practical utilisation of interleaves in the aerospace and automotive industries. We provide also a comparison of different interleaving materials, including scalability of manufacturing processes, effects on other composite properties, and the scope for achieving multifunctionality.

The literature giving strategies to improve damage tolerance of laminated composites is extensive and includes discussion of e.g. the reinforcement fibres and matrix system, composite manufacturing methods, interleaf structure and properties, and testing methods. Here, we constrain our analysis primarily to carbon fibre/epoxy composites-the most prevalent class of composite-and the characterisation of IFT and damage tolerance using established laboratory methods.

\section{Mechanical behaviour of composites}

Composites are materials systems that usually comprise reinforcing fibres embedded within a matrix. This provides improved properties over those delivered by the constituent materials alone [19]. CFRPs are a common example, where the carbon fibres, having higher tensile strength and stiffness than the plastic matrix, provide the reinforcement to the structure [1]. Other examples of reinforcement fibres include glass, aramids and cellulosics [20]. The continuous matrix is usually polymer, metal or ceramic, and when loads are applied to the composite, these are transferred from the matrix to the fibres. The matrix also isolates the fibres from one another, protects them from damage, and in cases of good interfacial bond strength, increases the toughness of the composite [21]. The properties of a composite material are determined by the ratio of fibres and matrix that it contains, their organisation within the structure, and the ability of the reinforcement fibre and the matrix to form a mechanical or chemical bond [1].

As discussed, composites are used in the automotive and aerospace industries due to their high levels of structural performance at lower mass than typical metallic alternatives. Their use in aircraft is no longer limited to smaller structures responsible for light loads, but they are increasingly used in heavily loaded primary structures: the F-35 Lightening II Joint Strike Fighter contains carbon fibre composites in the wing structure and fuselage [1]; the Boeing 787 Dreamliner aircraft body contains $50 \%$ by weight of composite materials [22], as does the Airbus A350 XWB [23]. When designing structural components from composites, knowledge of material properties such as elastic moduli parallel and perpendicular to the direction of reinforcing fibres, tensile strength in these directions, and shear strength is essential, as is an understanding of how the component will behave when subject to stresses under various loading conditions, including cyclic fatigue, and how much damage it can sustain before catastrophic failure. The latter is particularly important, e.g. wind turbine blades experiencing fluctuating loadings [24] or aircraft wings subject to bending-torsion flutter [25] may lead to microcracks and reduction of material strength.

We note that damage is not always immediately visible on components, so it is crucial that the part does not fail before damage can be identified and repaired. Comprehensive explanations of composite material mechanics and fracture mechanics are provided elsewhere $[1,26]$. Here, a general overview of the mechanics relating to fracture toughness and damage tolerance of composite materials is provided to guide our subsequent discussion of the effects of interleaving.

Composite laminates often possess microscopic defects from the manufacturing process. These can develop into larger cracks and result in delamination and failure of the part when applied with high stress, whether from the normal working conditions over time, or from impact of a foreign object such as a bird strike, hail or a dropped tool [27]. Determining fracture toughness and damage tolerance is therefore vital to inform the design of composite structures. A material's ability to resist the propagation of the crack, i.e. its ability to dissipate the strain energy that is released as a crack grows, is described by the fracture toughness of the material, first defined by Griffith [28]. Subsequently, Irwin [29] and Orowan [30] independently suggested that in the case of ductile materials, the majority of absorbed strain energy occurs through plastic deformation. This led to the use of critical strain energy release rate $G_{\mathrm{c}}$. The 
energy necessary for the crack propagation is balanced by the energy dissipation through creation of new surfaces, and other mechanisms such as plastic deformation. A crack will grow when the energy release rate; $G$ reaches a critical value: $G \geq G_{c}$ [31]. A material with a larger value of $G_{c}$, and therefore higher fracture toughness has a high capability for dissipating elastic energy during crack propagation, without catastrophic failure [32]. Failure can therefore occur in a fractured component at a lower stress than the ultimate strength of the defect-free part [33]. Once a crack in a material reaches a critical length, it can propagate spontaneously, resulting in failure of the part [34].

Composite materials are heterogeneous, usually exhibit structural and mechanical anisotropy, and are often brittle [35]. Commonly, FRPs are laminate structures with several layers of reinforcing fibre/fabric, with polymer matrix material between these. The interlaminar region provides a route through which cracks can preferentially propagate along the brittle matrix and thus can be susceptible to delamination. Under sufficient loading, composite materials will dissipate energy through various damage mechanisms, including delamination and fracturing, resulting in reduced stiffness and strength, thus compromising the function of the structural component.

Two classes of fracture dominate damage in laminates: when a crack propagates normal to the (inplane) fibre direction, translaminar or intralaminar cracking can occur, whereas when the crack propagates parallel to the fibres, interlaminar fracture, and hence delamination, occurs. Inevitably, this is a major constraint on the use of laminated FRP materials; as such, our focus in what follows is the significant body of research towards increasing IFT.

\section{Interlaminar fracture toughness}

Measuring interlaminar fracture toughness allows the delamination resistance of laminated composites to be determined. Structures made from composites are subjected to various types and directions of loading, synthesised by mode I, mode II and mode III test methods [36]. Mode I describes the tensile opening load, whilst mode II refers to the in-plane shear that occurs when a laminate undergoes bending, and mode III describes out-of-plane shear. IFT is often determined by calculating critical strain energy release rates $G_{c}$, from the data obtained through double cantilever beam (DCB) test for mode I loading, and end-notched flexure (ENF) test for mode II loading. Studies of IFT generally focus on the first 2 modes only since delamination growth is expected to be dominated by modes I and II [37].

The DCB test (BS ISO 15024-2001; ASTM D5528-13) is widely used for measuring mode I IFT of unidirectional composites [38]. Load and displacement data are recorded during the test, followed by use of one of several data reduction methods (Modified Beam Theory, Compliance Calibration method or Modified Compliance Calibration method) to calculate the critical strain energy release rate, $G_{\mathrm{IC}}$.

IFT under mode II loading can be determined through the ENF test, either by three (ASTM D7905M) or 4 bending points. For 3-point bending, there is 1 loading point on top of the specimen, with 2 supporting points underneath, whereas the 4-point bending test uses 2 loading points and 2 supporting points. Currently, there is a standard only for the 3-point bending ENF test. Arrese and Mujika [39] introduced correction factors to explain differences observed between measures of $G_{\text {IIC }}$ obtained through 3-point or 4-point ENF tests. They found that the difference between corrected and uncorrected $G_{\text {IIC }}$ values were larger for 4-point than for 3-point bending, indicating the 3-ENF was a more suitable method. Others, however, including Kuwata and Hogg [40] and Davies et al. [41] used a 4-point bending method in their studies. Wang et al. [42] reviewed several test methods for mode II fracture toughness and found that 4-ENF gives about $2 \%$ higher values for fracture toughness than the 3-ENF, and concluded that the 4-ENF test is effective for evaluating mode II propagation IFT. Martin and Davidson [43] argued that the 4-ENF was more stable and therefore more reliable. We note that loading stresses are constant between the two loading points on a 4-point bending test, whereas for 3-point bending, the stresses increase linearly from the supports, with only the centre of the specimen under the maximum stress [44]; as such the 4-point test induces a pure bending moment. For both methods, displacement data are collected as for the mode I tests, allowing calculation of the critical strain energy release rate under mode II loading, $G_{\text {IIC }}$.

Interlaminar fracture toughness is often used to evaluate the effect of an interleaf material, by comparing the value of $G_{C}$ of the interleaved composite 
against a non-interleaved control laminate. Throughout this review, all references to an increase or decrease in IFT are reported relative to the respective non-interleaved control, unless stated otherwise. Although the majority of these studies use essentially the same tests, such as DCB for mode I loading, it can be difficult to compare their results directly. Not only do different researchers use different composite systems-varying the number of plies, number of interleaves, woven or UD fabric, different resins, etc.- there can be differences in the reporting of $G_{C}$ values also. Most studies report an average $G_{C}$ value calculated from all the propagation points on the graph, sometimes referred to as $G_{C}$ PROP, whereas others use instead the initiation value of $G_{C}, G_{C-I N I T}$ [45], the nonlinearity point, $G_{C-N L}$ [36] or the 5\%/MAX point for mode I testing [46, 47] according to ASTM D5528-13 [48]. Others helpfully report both initiation and propagation values, whereas some do not elaborate how reported values of average $G_{C}$ have been calculated. Inevitably, this complicates comparison of data in the literature to understand how different interleaves affect composites.

Damage tolerance is the ability of a material to resist failure and continue to function despite the presence of a defect or damage [49] and is an important property of composite materials used for structural applications. Although initiation $G_{C}$ values indicate how easily the damage begins, i.e. the 'damage resistance', propagation values are considered a better indicator of damage tolerance. Measuring the compression response of a material after impact (CAI) is frequently used to determine the damage tolerance of composite materials.

\section{Impact damage resistance}

Impact testing is used to determine how a material will respond to a suddenly applied stress [50]. There are 2 main types of impact that aerospace components are exposed to: low velocity impact from a heavy object such as a dropped tool or piece of debris, and high velocity impact, typically from a smaller object such as a projectile. Energy from an impact can be dissipated through deformation, permanent damage, penetration or fragmentation; importantly, even relatively low energy impacts can cause internal damage to a composite structure, reducing its mechanical integrity [51].
For a low velocity impact, the ability of the fibres in the composite to dissipate energy through plastic deformation has a large effect on its impact resistance. Cantwell and Morton [52] reviewed the impact resistance of composites and found that for a given fibre used in the reinforcement, the area under the stress/strain curve is a good indication of its ability to absorb impact energy. They note also that although a larger diameter fibre should have higher intrinsic toughness, smaller diameter fibres give a higher strain to failure. This overcomes the reduced toughness of the thin fibres, resulting in a higher energy absorbing ability. Although Cantwell and Morton were examining the effect of the reinforcing fibre diameter, it follows that this may apply also to carbon fibres when used for interleaving, with the benefit that smaller diameter fibres will reduce the thickness of the interleaf. Low velocity impact can cause matrix cracking, which quickly leads to delamination [53]. Impact resistance and interlaminar fracture toughness are therefore related to one another; however whilst impact damage is a dynamic loading event, IFT is measured through quasi-static loading and therefore cannot fully describe impact behaviour [54].

Several test methods are used to measure resistance to impact damage and are described in detail elsewhere [51, 55]; here, we provide a brief overview of these. The Charpy impact test and Izod test are widely used and both involve testing of a notched specimen subjected to an impact from a pendulum. The impact energies to break notched and unnotched specimens are compared [51]. Drop-weight impact tests are also used; in these, a weight falls from a predetermined height, striking the test specimen, allowing the amount of energy dissipated to be determined [52].

Over 30 years ago, motivated by optimising composites for aerospace applications, Masters [56] investigated the use of ductile resin interleaves for toughening lamina interfaces in graphite/epoxy and graphite/bismaleimide composite systems. Although use of laminates in structural components has increased in the decades since Masters' study, interlaminar toughening of composites remains a major focus of current research. Various studies have found interleaving of fibrous mats or veils to increase impact resistance and damage tolerance of laminated composites. Yuan et al. [57] measured the impact response of carbon fibre composites interleaved with nonwoven aramid veils and observed around 40\% 
increase in residual compressive strength. Beckermann [58] notes that the improvement in impact resistance due to microfibre veil interleaves is often at the expense of other mechanical properties of the composite, suggesting that nanofibrous interleaves are better suited, though does not elaborate on this observation. Tsotsis [11], on the other hand, found that when interleaving with nonwoven veils, whilst impact resistance increased, other properties of the composite, such as open-hole compression, were not compromised. Tsotsis suggested that the interlayer could stabilise the reinforcing fibres and improve compressive properties when the veil is melt-bonded to the carbon fibre prior to infusion [11].

\section{Materials for interleaves}

We have noted that interleaves for toughening composites are made from a range of materials, such as polymer films, adhesives, resins, and nonwoven mats or veils. Nonwoven interleaves are made from different types of fibres including thermoplastics, carbon and nanofibres. Here, we group interleaves depending on their structure, i.e. film, microfibre and nanofibre; these can be further categorised based on the material, which is typically, but not exclusively, a polymer or carbon. CNT-based and hybrid interleaves combining 2 or more distinct materials are also discussed; examples of such hybrids include CNTs applied to a base material, and interleaves made from a mixture of fibre types.

Polymers are the most common type of material used in composite interleaving. Examples include polyamide (PA), polyester (PET), polyimide, polyethersulfone (PES), polyetheretherketone, polycaprolactone (PCL), polyaryletherketone Cardo (PEK-C), and polyvinylidene fluoride (PVDF), in the form of films, loose fibres or nonwoven veils. Other fibre types, such as carbon and aramids, are sometimes combined in hybrid interleaves to enhance their toughening capabilities, such as applying carbon veils with CNTs $[59,60]$ or combining aramid and phenoxy fibres [7]. In what follows, we provide a comparison of different interleaf types in order to elaborate and understand their toughening behaviour.

\section{Film interleaves}

Some studies have interleaved prepreg composites with polymer films and shown significant improvement in fracture toughness and impact resistance [61-63]. Aksoy and Carlsson [63] compared the fracture toughness of thermoset and thermoplastic films as interleaves in graphite/epoxy laminates under mode II loading. They attributed the toughening mostly to shear-yielding of the material around the crack tip and noted that an interleaf results in a larger crack tip yield zone and hence a higher fracture energy. They suggested also that the thermoplastic film exhibited superior toughening to the thermoset film, due to its high yield strength and strain to failure. In a study by Guo and Liu [64], PEK-C film interleaves with a 'lotus leaf-like' structure were designed to toughen CFRP. The surface structure of the films was produced via soft lithography, and phase separation of the PEK-C occurred, resulting in a thermoplastic rich layer with tough thermoplastic "nails". G IC $_{\text {iC }}$ ineased by only $17 \%$, but GIC $_{\text {IIC }}$ increased by over $300 \%$. This large increase in mode II IFT was attributed to the fracture path deflecting when close to the nails, giving a high energy dissipation. Yao et al. [62] compared the effect of using PEK-C as a matrix additive, a film interleaf and a particle interlayer. They found the film to be most effective at toughening the interlaminar regions of a carbon/ epoxy laminate made using prepregs, and attributed this to the presence of a 2-phase structure consisting of a PEK-C "peel" and rounded epoxy matrix regions wrapped by the PEK-C. They speculated that a large variation in fracture toughness seen for the particleinterleaved specimens was due to uneven particle distribution. Although such films can be very effective at toughening composites made from prepregs, they may be unsuitable for composites made via VARI or RTM, since non-porous films can impede the flow of resin through the layers of reinforcement fibre [13].

Several studies have explored porous films, compatible with VARI and RTM, that allow resin to flow through and fully wet out the reinforcing fibres. Cheng et al. [13] interleaved carbon/epoxy composites with polyethersulfone (PES) porous films with 'visible holes' at 1 hole $\mathrm{cm}^{-2}$. They saw an increase in mode I and mode II fracture toughness of $60 \%$ and $55 \%$, respectively. The films dissolved and phaseseparated in the epoxy matrix, and toughening was 
attributed to a combination of cohesive failure, and crack deflection by PES microspheres.

Van der Heijden et al. [65] studied glass/epoxy composites, comparing the toughening of various PCL interleaves: nanofibres, microfibres, microspheres, dense films, and glass fibres coated with a PCL spray. Under mode I loading, the porous microfibre, microsphere and nanofibre interleaves increased $G_{\text {IC }}$ by around $30 \%, 40 \%$ and $60 \%$, whilst the non-porous coated specimens and film interleaves increased by over $100 \%$ and $230 \%$, respectively. In contrast, under mode II loading, the opposite was observed: porous interlayers outperformed the non-porous. Microfibre and microsphere interleaves increased $G_{\text {IIC }}$ by around $50 \%$ and nanofibre by $80 \%$, whilst both the coated and film interleaves decreased $G_{\text {IIC }}$ by almost $30 \%$. Van der Heijden et al. noted although mode I fracture toughness increased, the non-porous interleaves hindered resin flow through the laminate and dense PCL interlayers had a detrimental effect on other mechanical properties of the composite. For the porous interleaves, they found that significant crack energy would be dissipated during interlaminar crossings of the crack path, where both PCL and epoxy fracture would occur. Although some film interleaves can increase IFT, particularly for prepreg laminates, recent research has focussed more on lightweight veil interleaves which can offer high porosity and open area [66].

\section{Microfibre veils}

Microfibre veils are defined here as being nonwoven materials made from fibres with mean diameter greater than $1 \mu \mathrm{m}$. Nonwoven materials consist of an arrangement of fibres formed into a web, mat or sheet through various techniques. There are several different types of nonwoven manufacture: "dry laid" nonwovens originate from textile production, "wet laid" from papermaking derived processes, and "spun laid" from polymer extrusion [67]. Nonwovens have applications in a diverse range of industries, including automotive, hygiene, filtration, geotextiles, construction and clothing. Nonwovens can often be produced in large quantities cheaply; combined with high porosity and absorbency, this makes them wellsuited for the disposable and hygiene industry. These same characteristics make them suitable for composite interleaves. In addition to their low cost and ease of manufacture, characteristics such as thickness and mass per unit area, or areal density are controllable, allowing relatively straightforward manufacture of veils with different properties through selection of fibre types and dimensions [68]. The term "veils" used throughout this review refer to any nonwoven fibre network, including electrospun nanofibre networks, although we note that the nonwovens industry often uses "mats" above a certain areal density threshold.

The earliest use of a veil in an interleaf system probably dates to 1985, when American Cyanamid submitted a patent [69] for an interleaved prepreg system. The interlayer comprised a thermoset epoxy resin containing a rubbery polymer and a nonwoven fibrous web. Importantly however, the nonwoven layer was not considered the reinforcing component of the interleaf: instead its role was to deliver the resin to the desired location within the composite. Subsequently, fibrous interleaves have been found to be effective for interlaminar toughening in their own right. In particular, nonwoven veils can provide interlaminar toughening through mechanisms such as fibre bridging, fibre pull-out or breakage, and plastic deformation, such that the composite system absorbs more energy during crack propagation, resisting further crack growth. We note that fibrous interleaves can also cause the crack path to be deflected, which helps to dissipate more crack energy [11]. We proceed to discuss the various materials systems studied as candidates to deliver these advantages and the mechanisms that determine their effectiveness.

\section{Polymer veils}

Tsotsis [11] carried out a systematic investigation into the use of various polymer veil types on the impact resistance of carbon/epoxy composites. All interleaves used were spunbonded veils, which were melt-bonded to the unidirectional carbon fabric prior to composite lay-up. Initial results showed laminates interleaved with polyamide-based veils to give higher CAI strength than those interleaved with polyester veils; however, for all veils tested, the increase was lower when specimens were saturated with water at elevated temperature; this being termed the 'hot/wet' performance. This was attributed to moisture absorption by the hygroscopic veils resulting in lowered melting point. The fairly high 
level of moisture absorption, around $2.5 \%$, of polyamide [70] could make composite parts manufactured with PA interleaves susceptible to changes in mechanical behaviour in varying environmental conditions. Walker and $\mathrm{Hu}$ [71] studied the mode I delamination behaviour of short fibre-reinforced carbon/epoxy composites following environmental conditioning, which involved immersion in water at $96{ }^{\circ} \mathrm{C}$ for $600 \mathrm{~h}$. Although the PA interleaved samples gave an increase in IFT, the PA webs hydrolysed during environmental treatment which caused a weakening of the interlaminar region. This suggests that moisture absorption may reduce any toughening effect provided by a PA interleaf. Following initial tests, Tsotsis emphasised that although polymer veils can significantly improve CAI strength in composites, compatibility between the matrix and veil is important if other mechanical properties are to be maintained. Using veils with melting points above $150{ }^{\circ} \mathrm{C}$ resulted in smaller improvements in CAI. A polyamide-based veil with reduced fibre diameter, such that more fibres would be present per unit area for a given areal density of veil, was used as an interleaf on the assumption that that a crack would have to go over, around or through more filaments to propagate further through the material, dissipating more energy in the process. This reasoning is consistent with that of Ramirez et al. [36], who found a relationship between fracture toughness of interleaved composites and the mean coverage of the veil, where coverage is a structural property of a fibre network, defined as the average number of fibres covering points in the plane of the network [72]. For both mode I and II, they reported an increase in fracture toughness with increasing coverage, up to a plateau, suggesting there may be an optimum amount of fibre coverage in a veil to give maximum toughening effect to the interlaminar region.

We use the concept of coverage in our subsequent analysis of results from the literature, so provide a brief overview of its dependencies here. Coverage is dependent on fibre diameter, so, if the polymer type and areal density are constant, then reducing fibre diameter will increase the coverage. Mean coverage is given by the ratio of the mean areal density of the network, to that of the constituent fibres. The mass per unit area of fibres is given by the ratio of the linear density to the fibre width, so the mean coverage is [36] $\bar{c}=\frac{\bar{\beta} \omega}{\delta}$

where $\bar{c}$ is mean coverage, $\bar{\beta}$ is the mean areal density of the veil $\left(\mathrm{kg} \mathrm{m}^{-2}\right), \omega$ is fibre width $(\mathrm{m})$ and $\delta$ is the linear density of fibres $\left(\mathrm{kg} \mathrm{m}^{-1}\right)$.

For fibres of circular cross section, the width is the fibre diameter, though the use of width to characterise the transverse dimension of fibres permits application of Eq. (1) to other fibre morphologies, such as ribbons. We note that the linear density of fibres of arbitrary cross section is given by the product of the cross-sectional area and bulk density, $\rho$, so in the case of circular cross section with diameter, $\omega$, we have $\delta=\pi \omega^{2} \rho / 4$ such that $\bar{c}=4 \bar{\beta} /(\pi \omega \rho)$. Importantly, where Ramirez et al. [36] found 2 relationships for plots of fracture toughness against areal density, $\bar{\beta}$, for PPS veils formed from different fibres with different diameters, their data collapsed to a single curve when fracture toughness was plotted against mean coverage, $\bar{c}$.

Kuwata and Hogg [40,73] also explored the effect of nonwoven veil interleaves on mode I and mode II IFT of CFRPs. Whereas Tsotsis [11] found polyamide veils to out-perform polyester, Kuwata and Hogg's polyester veil outperformed carbon, polyamide and carbon/polyester hybrid veils for $G_{\text {IC-NL }}$ and $G_{\text {IC-PROP }}$ when interleaved in a UD carbon/epoxy laminate. The percentage increase in $\mathrm{G}_{\mathrm{IC}-\mathrm{NL}}$ of $50 \%$, however, was lower than for a similar PET veil used by Quan et al. [74], which gave an increase of $80 \%$. A PPS veil of similar areal density used by Ramirez et al. [36]

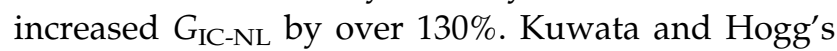
carbon and PA veils decreased the mode I fracture toughness and had fairly modest increases in mode II.

The polyester and carbon hybrid veils studied by Kuwata and Hogg [40, 73] had fibre diameters of 9-13 $\mu \mathrm{m}$, used in the ratio 70:30 and 80:20. The hybrid veils had little effect on the $G_{I C}$ fracture toughness of the UD carbon/epoxy laminate and decreased the $G_{\text {IC-PROP. }}$ For mode II loading however, the $G_{\text {IIC-PROP }}$ for the 80:20 PET/carbon veil was almost double that of the control. The authors suggested that the inability of the carbon fibre in an interleaf to deform during crack propagation may have decreased the veil's effectiveness. They mention also that in addition to the quality of the interface between fibre and matrix, other factors may affect an interleaf's 
toughening ability, including its uniformity, mean porosity and fibre diameter; from Eq. (1), we note that this latter parameter influences the mean coverage of the veil and discuss this further in what follows.

Zheng et al. [75] studied a hybrid interleaf consisting of an electrospun PA66 nanofibre veil embedded within a PCL matrix. Each interleaf material used separately produced only moderate increases in $G_{\text {IC-PROP }}$ of $30 \%$ and $50 \%$ for PA66 and PCL, respectively, but was doubled when the materials were combined. Similarly in mode II, the individual components each gave an increase of fracture toughness of $20 \%$, whereas for the hybrid system the increase was $100 \%$, demonstrating significant synergistic effects. The improved toughening was attributed to crack deflection caused by PCL agglomerates. Additionally, interfacial adhesion between the hybrid interleaf and epoxy was increased, with the authors suggesting that PCL that had not completely phase separated in the epoxy formed "molecular interlocks" with PCL on the nanofibres. Combining different materials will inevitably complicate the manufacturing process for interleaves; however, the combined properties of the resultant hybrid material could justify a more expensive and complicated process. This is discussed further in subsequent sections.

In similar work, Wong et al. [76] used dissolvable thermoplastic phenoxy as a chopped fibre interleaf in carbon/epoxy composites. They saw a significant increase in $G_{\text {IC }}$ of the laminate when $10 \%$ wt phenoxy was added, as well as improved tolerance to impact damage. In fact, a phenoxy toughening system, which consists of the phenoxy toughener combined with the composite reinforcing fabric, has been commercialised [77]. Similarly, Zheng et al. [78] interleaved dissolvable PES fibres into carbon/epoxy composites and saw a fivefold increase in $G_{I C}$ with the addition of $10 \%$ wt PES fibre.

We find that it is not uncommon for studies to report data for one of mode I or mode II IFT, but not both. Those that do measure both often find that one mode is affected significantly more than the other, e.g. an increase in $G_{I C}$ over $10 \times$ higher than the increase for $G_{\text {IIC }}$ [79], or an increase in $G_{\text {IIC }}$ almost double [80] or over $8 \times[81,82]$ that of $G_{\text {IC. }}$ With a limited number of studies that investigate both modes, it is difficult to establish the reasons for this difference. Although it is more common among the literature to see higher increases in mode I IFT, mode
II is considered more relevant to the fracture mechanisms in impact damage [83] and therefore a better indication of the damage tolerance of a composite.

\section{Carbon veils}

Lee et al. [81, 82] studied the effect of interleaving nonwoven carbon veil prepregs between layers of a CFRP laminate. The carbon veil contained randomly oriented short carbon fibres with areal density $12 \mathrm{~g} \mathrm{~m}^{-2}$ which was combined with an epoxy resin film to form a prepreg. They found that the carbon interleaf had a much greater effect on mode II than mode I IFT. The mean $\mathrm{G}_{\mathrm{IC}}$ decreased by $5 \%$ when using a single veil at the mid-plane and yielded a moderate increase of around $30 \%$ with multiple veils. In contrast, $G_{\text {IIC }}$ increased by over 200\%. They attributed this increase to short fibre bridging from the carbon fibres in the interleaf. Kuwata and Hogg $[40,73]$ used a similar $10 \mathrm{~g} \mathrm{~m}^{-2}$ carbon veil in their study and found only a small increase in mode II IFT and a decrease in mode I $G_{\text {IC-NL. They did however }}$ see slightly larger increases in both mode I and mode II mean $G_{C}$ values when using a polyester/carbon hybrid veil. Although there are very few examples within the literature of using carbon veil interleaves, some studies use them in combination with CNTs; we discuss these shortly.

\section{Nanofibre interleaves}

As might be anticipated, the unique properties of nanomaterials have resulted in the study of CNTs and nanofibres for interleaving. Nanofibres have diameters less than $1 \mu \mathrm{m}$ and an aspect ratio (length/diameter) typically larger than 100 [84]. There are several methods that can be used to produce nanofibres: template synthesis, self-assembly, melt blowing, drawing, electrospinning and centrifugal spinning [85]. Electrospinning, being simple and inexpensive, is widely applied for research into nanofibre interleaves [86]. Electrospun nanofibres have high specific surface area, good flexibility and controllable diameter, and yield networks with high porosity [73] making them well-suited for composite interleaves.

Although electrospinning was first invented around 1930, improvements in the instrumentation and working parameters over the last 30 years have revealed the potential of this technique [87]. The 


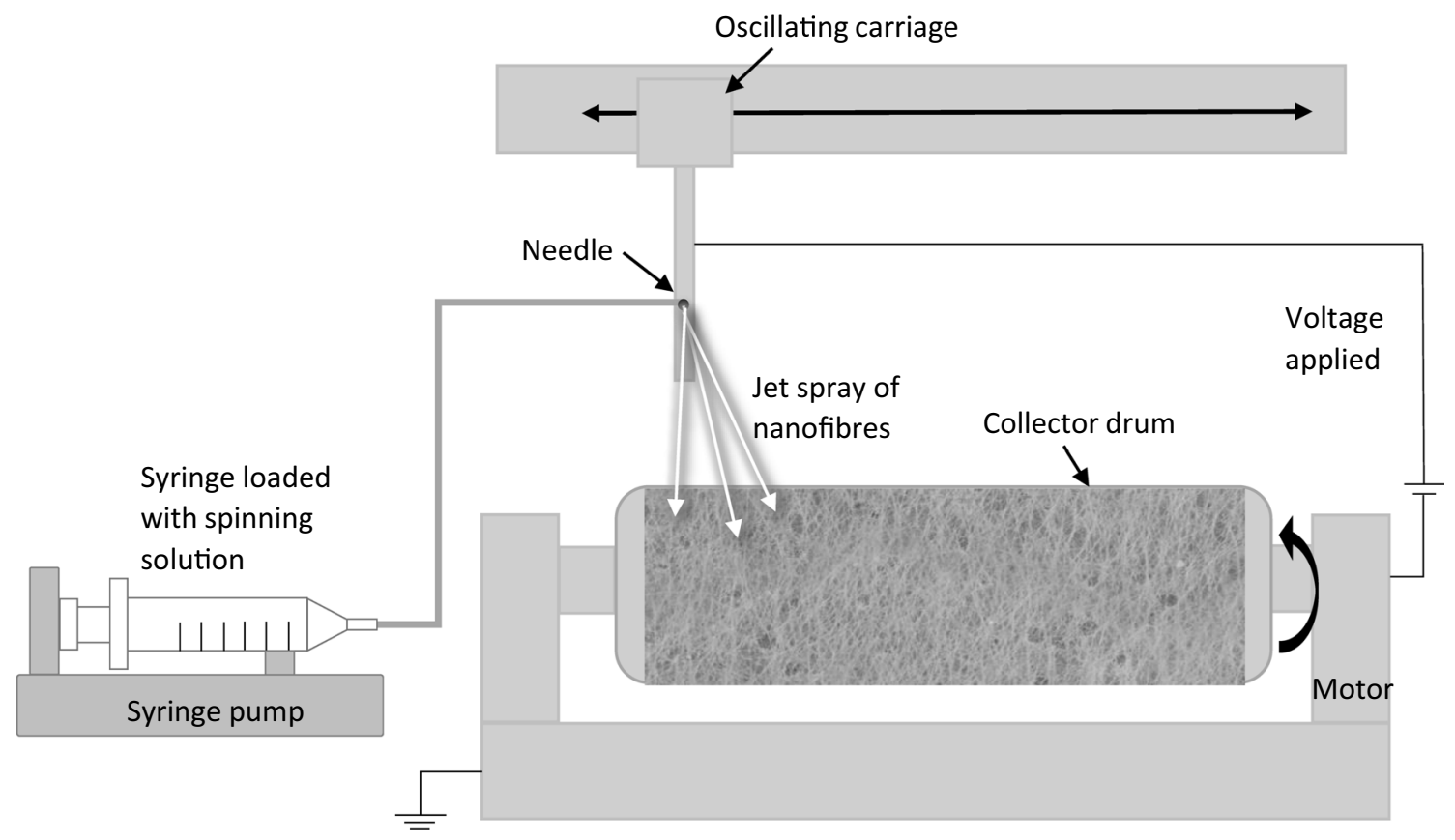

Figure 1 Generic electrospinning process using a spinneret on a mandrel.

electrospinning process involves the stretching and stochastic splitting of a polymer solution under a high electric field into filaments, yielding nanofibres to be collected in a near-random orientation on the target [84], as depicted schematically in Fig. 1. The polymer is supplied via the spinneret and the jet of fibre is ejected from the vertex of the cone that is formed when the electrostatic force exceeds the surface tension of the polymer solution [86]. The high elongation of the solidifying jet enables the spontaneous orientation of the macromolecular chains along fibre direction, which contributes to an increase in the modulus and strength of a single fibre [88]. There are also needleless electrospinning methods, which may be more suited to large-scale production. For detailed discussion of electrospinning methodologies, parameter optimisation to produce networks with desired properties, free from beading and other defects, see, for example $[85,89,90]$.

During electrospinning, a web or veil of fibres is collected on the drum or plate. This can then be added to the composite lay-up by being placed between plies of reinforcing fabric, as done by Beckermann and Pickering [45] and Daelemans et al. [91]. Alternatively, electrospinning can be carried out directly onto dry carbon fabric or prepregs, as done by Beylergil et al. [92] and Magniez et al. [93]. Scanning electron microscopy (SEM) is typically used to

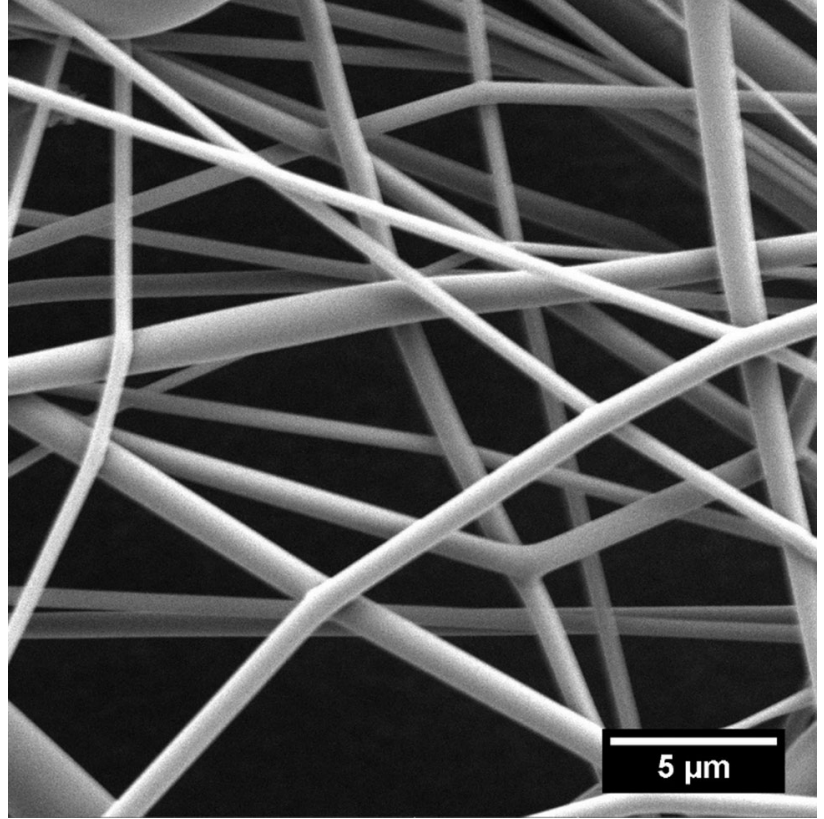

Figure 2 Micrograph of electrospun PET fibres with areal density about $1 \mathrm{~g} \mathrm{~m}^{-2}$ and mean fibre diameter around $800 \mathrm{~nm}$.

reveal any defects in the nanofibrous structure such as beading, and allows fibre diameter and porosity to be determined [94]. Figure 2 provides an example of an SEM micrograph of an electrospun PET fibrous veil obtained during our work on these materials. 
An early study of the effect of nanofibres on mechanical properties of composites is provided by Kim and Reneker [95], who used poly-benzimidazole nanofibres to toughen an epoxy. Research into these materials has developed considerably over recent years, as they are natural choices to increase IFT with little weight penalty. The review of Palazzetti and Zucchelli [18] provides a comparison of literature data, including the polymer type, nanofibre diameter, the thickness or areal density of the veil, manufacturing type, lay-up and $G_{\text {IC }}$ or $G_{\text {IIC }}$ data. They noted that the majority of studies reviewed investigated PA nanofibre veils with the use of prepregs being the most common type of laminate manufacture. Wang et al. [96] also reviewed use of nanofibres as reinforcement in polymer composites, exploring use of polymer and non-polymer nanofibre reinforcement, discussing the potential of these materials as well as current research challenges.

Polyamide (PA) has been used to produce electrospun fibres for interleaving in several studies [45, 91, 92, 97]. Beckermann and Pickering [45] attributed this polymer choice to the compatibility of PA66 with the epoxy matrix, as well as the high intrinsic toughness, strength and ductility of the polymer. PA is also cheap, can be easily dissolved for electrospinning, and has a melting point higher than most curing temperatures [18]. Daelemans et al. [91] cite Beckermann and Pickering's work when justifying their use of PA fibres. A comparison of PCL, PA 6 and PA 6.9 nanofibrous interleaves with areal density $14 \mathrm{~g} \mathrm{~m}^{-2}$ is reported by Daelemans et al. [98]. They observed increased fatigue delamination resistance for all polymer types, with PCL interleaved laminates giving the greatest increase over the range of loads tested. Magniez et al. [93], using PVDF fibres interleaved in carbon/epoxy composites, saw an increase in mode II fracture toughness of around $60 \%$ and a decrease in mode I of 20\%. Zhang et al. [99] compared PCL, PVDF and PAN nanofibres, but observed toughening only for the PCL. Saghafi et al. [100], on the other hand, observed an increase of over $40 \%$ in mode I fracture toughness when interleaving with PVDF nanofibres. These collected results illustrate clearly that identification of the factors affecting the fracture toughness of interleaved composites is complex and dependent on variables other than nanofibre polymer type.

Zhang et al. [101] investigated interleaves of both phenoxy films and electrospun phenoxy fibres and found that both yielded significant increases in mode I IFT. For both, the phenoxy dissolved in the epoxy matrix, with dissolution rate determined by the specific surface area of the interleaf: film dissolving more slowly than fibrous interleaves. They concluded that the slower dissolution of the film interleaf was beneficial to toughening since the phenoxy from the film remained within the interlaminar region during cure, whereas that from the faster-dissolving fibrous interleaf migrated through the epoxy matrix, resulting in uneven distribution. Accordingly, Zhang et al. suggest that fibrous interleaves may be more beneficial when using polymers with higher $T_{\mathrm{g}}$.

Beckermann and Pickering [45] tested composites with interleaves electrospun from a range of polymers; they found that PA66 nanofibre veils with an areal density of $4.5 \mathrm{~g} \mathrm{~m}^{-2}$ gave the largest increase in IFT of over $150 \%$ for mode I and $70 \%$ for mode II. We note that the mode I measure reported is the critical strain energy release rate for the crack initiation from the release film during the pre-test, ' $G_{I C-o n s e t}$ insert', whereas most studies report either the nonlinearity point, $G_{\text {IC-NL }}$ as the crack grows from the pre-crack upon reloading, or the mean propagation, $G_{\text {IC-PROP. }}$ Although Beckermann and Pickering provide their $G_{\text {IC-NL }}$ (referred to as ' $G_{\text {IC-onset }}$ pre-crack') and $G_{\text {IC-PROP }}$ values, these show an increase of around $30 \%$ and a decrease of $6 \%$. They argue that ' $G_{\text {IC-onset insert' }}$ (crack initiation during the pre-test) is the correct measure of the toughness of the interlayer, since after around $6 \mathrm{~mm}$ of crack growth, the crack moved outside the toughened region of the laminate; as such, the other $G_{I C}$ values measure the untoughened laminate. Of course, in practical contexts, if an interleaf is to provide effective toughening, then it is imperative that crack propagation is constrained within the toughened region. We shall return to this discussion in our subsequent comparison of nanofibre and microfibre interleaves.

Beckermann and Pickering's [45] composites were manufactured using carbon prepregs, with the veils added to the mid-plane after being electrospun onto a wax paper. Subsequently, Beckermann [58] describes a similar commercial product, 'Xantu Layr' [102] made by electrospinning nanofibres onto a silicone release paper, and then transferred onto prepreg carbon fabric using pressure applied by a heated roller, before peeling off the backing sheet to leave the layer of nanofibres adhered to the tacky resin of the prepreg. In contrast, Magniez et al. [93], 
electrospun fibres directly onto a carbon prepreg and Beylergil et al. [92], electrospun fibres directly onto the carbon fabric prior to the manufacture of the composite panel via vacuum infusion. Zhang et al. [103], also electrospun directly onto dry carbon fabric and argued that depositing nanofibres onto prepregs could cause incomplete toughening of the entire resin layer, whereas adding the epoxy to the lay-up should ensure take-up of the entire resin layer by the nanofibres. In industrial contexts, time and cost could be reduced by electrospinning directly onto carbon fabrics [18], although a ready-made interleaf product may be preferable where capital outlay on electrospinning equipment may not be justified.

Daelemans et al. [104] investigated the toughening micromechanisms in interleaved carbon fibre/epoxy prepreg laminates by testing the effect of electrospun PA 6.9 nanofibre veils with different alignments. They interleaved veils with nanofibres preferentially oriented in the direction of crack growth, perpendicular to it, and randomly oriented. They found that randomly oriented fibres gave the largest increase in mode II IFT; after analysis of the fracture surfaces and crack path, they associated this toughening effect with the improved development of nanofibre bridging zones, in agreement with earlier work [91]. Defining the increase in toughness during "subcritical crack growth" as

$\Delta G_{\text {IIC }}=G_{\text {IIC-INI }}-G_{\text {IIC }-\mathrm{NL}}$

Daelemans et al. [104] proposed that a more effective bridging zone is characterised by a larger $\Delta G_{\text {IIC }}$ and that this is therefore a measure for the effectiveness, or "size" of the nanofibre bridging zone. They note, however, that $\Delta G_{\text {IIC }}$ is related also to the complex crack growth mechanism and is therefore not a measure of nanofibre bridging only.

Beckermann and Pickering [45] also attribute the improved fracture toughness achieved with electrospun veil interleaves to the bridging of microcracks in the interlayer during mode II fracture, whilst noting that the toughening mechanisms are not fully understood. They cite Xia and Hutchinson [105], who describe failure under mode II loading as resulting from combined shear and tensile microcrack growth. Since nanofibre bridging absorbs crack energy, Beckermann and Pickering note that high tensile strength nanofibres sufficiently bonded to the matrix will resist microcrack opening and hence result in a higher mode II IFT.

Daelemans et al. [106] conducted a multi-scale analysis of the toughening mechanisms of glass fibrereinforced composites interleaved with electrospun nanofibres. They argued that to optimise interleaf toughening, understanding of nanofibre micro-mechanics is required. They conducted a multi-scale analysis of nanotoughened epoxy, a single nanotoughened interlaminar region, and a laminate with nanofibre interleaves in each interlaminar region. They found nanofibre veils to have a significant effect at the laminate level, as well as on a microscopic and interlaminar level and identified the number of crossings a crack makes through the interlaminar region as the main contributor to composite toughening, since nanofibre bridging zones develop in these regions. As such, we find a broad consensus that nanofibre bridging plays a major role in the toughening of the interlaminar region, though the efficacy of bridging will depend on the mechanical properties of the nanofibre and adhesion between interleaf and matrix [107].

\section{Effect of nanofibre diameter}

The dimensions of fibres formed during electrospinning depend on several parameters. The properties of the polymer itself will have an effect, including molecular weight, glass-transition temperature and solubility, as well as the properties of the polymer solution: viscosity, viscoelasticity, concentration, surface tension, and electrical conductivity [108]. The vapour pressure of the solvent and the relative humidity of the spinning environment can also have substantial influence. In addition, the substrate properties, the feed rate of solution, and the field strength and geometry of the electrodes play a major role in the formation of the nanofibres [108]. Whilst noting that these parameters allow control of nanofibre dimensions in electrospun veils, in what follows we focus only on the effect of the dimensions of the resultant fibres on the performance of the interleaf.

Zhang et al. [103] investigated the effect of nanofibre diameter on mode I interlaminar fracture toughness of composites, using dissolvable electrospun PEK-C. The average diameters of the PEK-C nanofibres tested were 450, 750 and $950 \mathrm{~nm}$, with the smallest fibre diameter giving the highest strain 
energy release rate for crack initiation ( $\left.G_{\text {IC-INI }}\right)$. Beckermann and Pickering [45] investigated the effect of electrospun fibre diameter on laminate toughness for non-soluble polymers. For electrospun polyvinyl butyral (PVB) nanofibre networks with areal density around $4 \mathrm{~g} \mathrm{~m}^{-2}$, they observed no significant difference between interleaved laminates with fibre diameters between 400 and $700 \mathrm{~nm}$ and those with diameter between 700 and $1000 \mathrm{~nm}$. Accordingly, they concluded that veil fibre diameter variations in the nanometre range do not influence laminate fracture toughness. Recall from Eq. (1) that for networks formed from a given polymer and areal density, fibres with different diameter yield networks with different mean coverage. Ramirez et al. [36] reported an increase of mode I and mode II IFT for interleaved PPS veils in epoxy with mean coverages below about 4 , above which IFT was very insensitive to mean coverage. From Eq. (1), we estimate the mean coverages of Beckermann and Pickering's [42] PVB nanofibre and microfibre networks to be around 9.2 and 6.2, respectively, and as such were above the threshold below which any sensitivity to fibre diameter might be expected.

\section{Nanofibre versus microfibre}

A major difference between nanofibres and microfibres is their greater specific surface area, this being inversely proportional to their diameter. In principle, this should be beneficial for interleaves, since there is more polymer surface available per unit mass for bonding to the matrix, and for strain energy transfer. Similarly, we expect nanofibres to offer advantages over microfibres due to their superior mechanical, electrical and thermal properties.

Following Ramirez et al. [36], other groups have shown a dependence of IFT on the areal density of the interleaving veil. A linear relationship up to a point between areal density of microfibre interleaves and IFT was reported by Chen et al. [109] and Beylergil et al. [92, 110]. In general, we observe that IFT data from the literature usually show significantly higher increase in mode I and mode II fracture toughness for microfibre interleaves than nanofibre ones. Now, recall that Ramirez et al. [36] found the mode I and mode II IFT of composites interleaved with PPS veils to be independent of the linear density of the constituent fibres when plotted against mean coverage, whereas there was a dependence when plotted against areal density. From Eq. (1), we note that at a given areal density, a veil consisting of smaller diameter fibres has greater coverage. As such, the same coverage can be achieved for a nanofibre veil at considerably lower areal density than a microfibre veil. In what follows, we reinterpret dependencies of IFT reported in the literature in terms of the coverage of the interleaf.

The use of electrospun PCL veils on the IFT of glass-fibre/epoxy composites was studied by van der Heijden et al. [65]. A nanofibre interleaf gave a larger increase in both mode I and mode II IFT than a microfibre interleaf of the same areal density; this was attributed to the 'fine distribution' of PCL, compared to the microfibres, which had a 'less homogeneous distribution'. This is consistent with theory describing the in-plane distribution of mass in

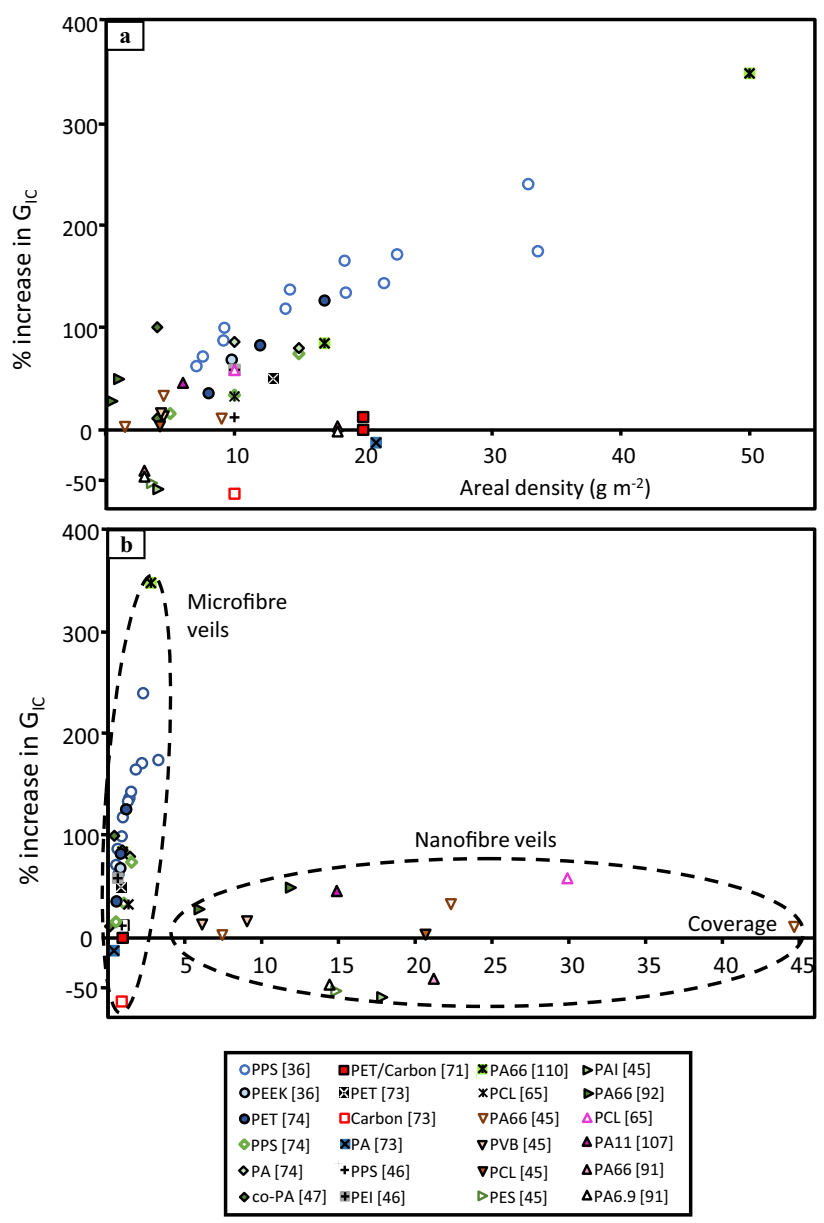

Figure 3 Percentage increase in mode I fracture toughness, $\mathrm{G}_{I C}$ plotted against $\mathbf{a}$ areal density and $\mathbf{b}$ coverage of the interleaf. Data from the literature as indicated by reference numbers in the legend. Dotted ellipses illustrate the clustering of data from microfibre veil interleaves and nanofibre veil interleaves. 
random fibrous networks, where the variance of local areal density is proportional to the linear density of fibres at a given areal density and inspection zone size [68, 111]. van der Heijden et al. [65] describe how the smaller zones of PCL in the nanofibre interlayer were well impregnated with epoxy, making the interlaminar region both stiff and tough. The authors also emphasise their findings from previous studies $[106,112]$ concerning the importance of bridging and interlaminar crossings during crack propagation.

A comparison of $G_{I C}$ and $G_{I I C}$ data from both microfibre and nanofibre interleaved composites collected from the literature is provided in Figs. 3 and 4. Although there is some variation in materials and methods between different studies, those used to create Figs. 3 and 4 all used carbon fabric as reinforcement, except van der Heijden et al. [65] who used glass, with an epoxy matrix, and used either a
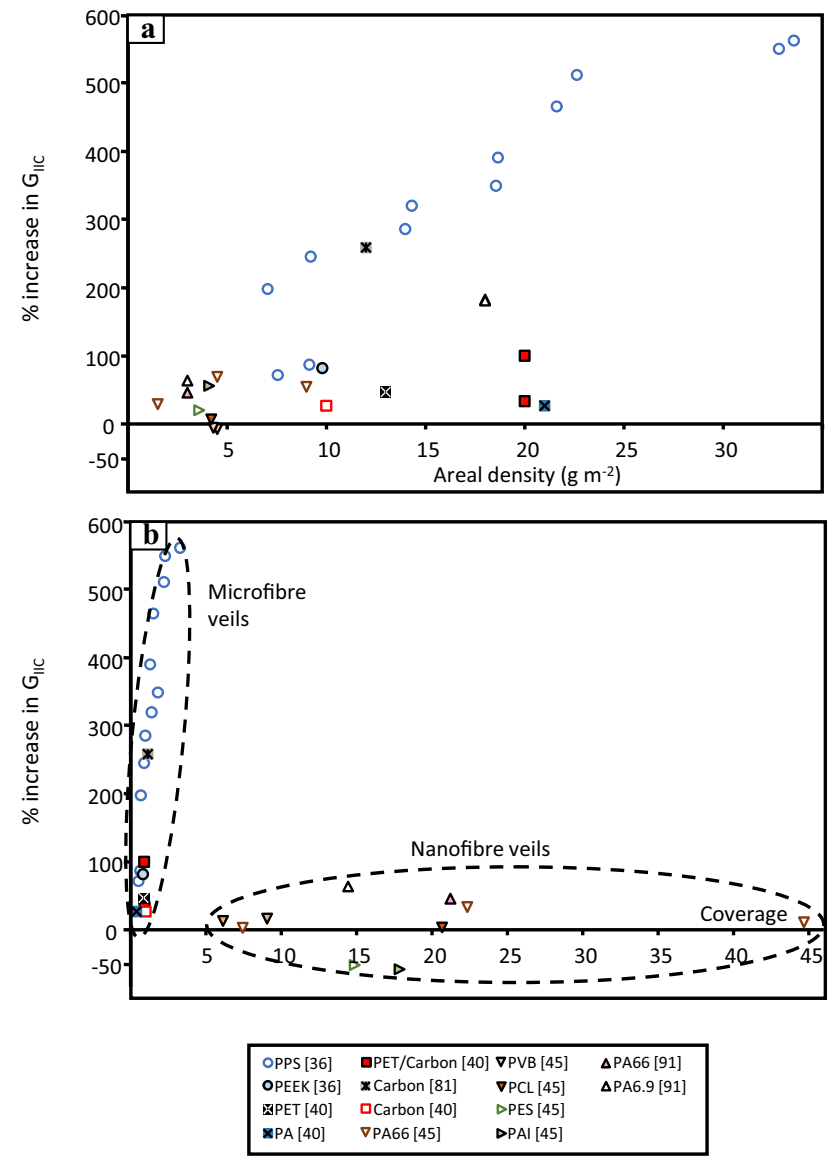

Figure 4 Percentage increase in mode II fracture toughness, $\mathrm{G}_{\text {IIC }}$ plotted against $\mathbf{a}$ areal density and $\mathbf{b}$ coverage of the interleaf. Data from the literature as indicated by reference numbers in the legend. Dotted ellipses illustrate the clustering of data from microfibre veil interleaves and nanofibre veil interleaves. microfibre or nanofibre interleaf for toughening of the interlaminar region. Typically, authors report the areal density of their interleaves, the width of the fibres and polymer used allowing calculation of the mean coverage for their data; where the density of the polymer was not provided, we have assumed a typical value. To allow comparison among data with different values for the control, i.e. non-interleaved composite, we have calculated the percentage change in $G_{C}$ and have plotted this against the areal density of the veil in Fig. 3a, and against the mean coverage of the veil in Fig. 3b.

In Fig. 3a, we see a general increase in $G_{\text {IC }}$ with areal density, though we note that at areal densities above $20 \mathrm{~g} \mathrm{~m}^{-2}$ the data are dominated by those of Ramirez et al. [36]. At lower areal densities, the data show no discernible trend. Figure $3 b$ shows these same data for $G_{\mathrm{IC}}$, but now plotted against the coverage of the veil, as calculated from Eq. (1).We observe a clear demarcation between data for nanofibres, all identified by triangular data markers, and those for microfibres. Corresponding plots for mode II are shown in Fig. $4 a, b$ and we observe the same clear demarcation between $G_{\text {IIC }}$ for interleaves of nanofibres and microfibres as we saw for $G_{I C}$. It is important to note that the strong dependence of IFT for interleaves formed from microfibre veils arises despite the data coming from independent studies, where a broad range of processes were used to prepare composites. Further, the dependence of $G_{I C}$ and $G_{\text {IIC }}$ shows a surprisingly weak sensitivity to the material used in the veil.

The microfibre veils giving rise to the data in Figs. 3 and 4 all have coverage less than about 4, whereas for the nanofibre networks formed by electrospinning, we observe much higher coverages and at best only modest increases in fracture toughness that are largely insensitive to coverage. We speculate that this is a direct consequence of these high coverage nanofibrous veils behaving more like continuous films due to their much smaller open area and pore size and elaborate on this below.

In a random fibre network, if the mean coverage is less than, say 2, most fibres in the veil are in the network surfaces [113] and we can assume negligible $z$-direction structure such that the veil is effectively 2-dimensional and its porosity, $\varepsilon$, is the fraction of its area not covered by fibres, i.e. the fraction of holes or 'through-pores'; for a random network this is given 
by $\varepsilon=\mathrm{e}^{-\overline{\mathrm{c}}}$ [68]. At higher mean coverages, veils have appreciable thickness such that porosity is no longer determined by the coverage, but depends primarily on the flexibility and conformity of the constituent fibres and, for example, pre-processes such as pressing. Regardless of coverage, we can obtain the mean pore size, $\bar{d}$ as encountered at the surfaces of the veil by resin in an infusion process as follows [114]:

$\bar{d}=\frac{2 \omega}{\ln (1 / \varepsilon)}$

A crude estimate of the capillary pressure required to impregnate resin into a veil can be obtained by applying the Young-Laplace equation,

$\Delta P=\frac{4 \gamma \cos (\theta)}{\bar{d}}$

Combination of Eqs. (3) and (4) yields

$\Delta P=2 \gamma\left(\frac{\ln (1 / \varepsilon)}{\omega}\right) \cos (\theta)$

where the terms in parentheses are properties of the veil. So, for given resin properties and veil porosity, the inverse dependence of $\Delta P$ on $\omega$ means that a consequence of using electrospun veils of fibres with diameters of a few hundred nanometres [45] instead of veils of macrofibres, with diameters of order $10 \mu \mathrm{m}$ [36] increases the pressure required for impregnation of the veil by around 2 orders of magnitude; further if the porosity of the electrospun network is, say $60 \%$, compared to the $95 \%$ porosity typically observed for a microfibre wet laid nonwoven, the pressure for impregnation increases by another order of magnitude. On this basis, we speculate that even at low grammages, the coverage of electrospun veils is sufficiently high that even at the high porosities that are characteristic of these materials, the pore size is sufficiently small to inhibit resin infusion into the network. As such, a propagating crack will tend to rapidly move from the veil to the matrix, consistent with the behaviours observed in Figs. 3 and 4.

Recall that this movement of the propagating crack from the interleaf into the matrix was used by Beckerman and Pickering [45] to justify their use of initiation data to characterise IFT and by Maccaferri et al. [79] who chose to discount data considered to arise from movement of the crack plane away from the toughened interlayer of hybrid interleaves of PCL nanofibres and Nitrile Butadiene Rubber (NBR). Chen et al. [115] attempted to constrain the crack path within the interleaf using fusion-bonded dots on a polyamide microfibre veil. This reveals an important challenge in moving from improved performance in laboratory assessments of fracture toughness to improved performance of composites in end use applications: whereas veils may offer a route to improve fracture toughness, the practical challenge may development of composite architectures that retain the crack within the toughened region.

\section{Carbon nanotube interleaves}

The use of carbon nanotubes (CNTs) for toughening of composites is the subject of several recent reviews [14-16]. We discuss these briefly, with our primary focus being the toughening mechanisms involved, how these compare to fibrous interleaves, and approaches to incorporate CNTs within an interleaf.

CNTs consist of a tube-shaped lattice, the walls of which are one carbon atom thick in the case of singlewalled carbon nanotubes (SWCNTs), or consist of several layers in multi-walled carbon nanotubes (MWCNTs) [116]. These can be incorporated in a composite in several ways: adding them to the matrix [54], spraying onto the reinforcing plies [117], or incorporating them within a veil $[59,60]$.

Lee et al. [59] used CNTs embedded within carbon fibre veils and observed an increase in mode I of over $30 \%$ and mode II of around $250 \%$. The carbon veils used without CNTs gave a decrease in mode I IFT of

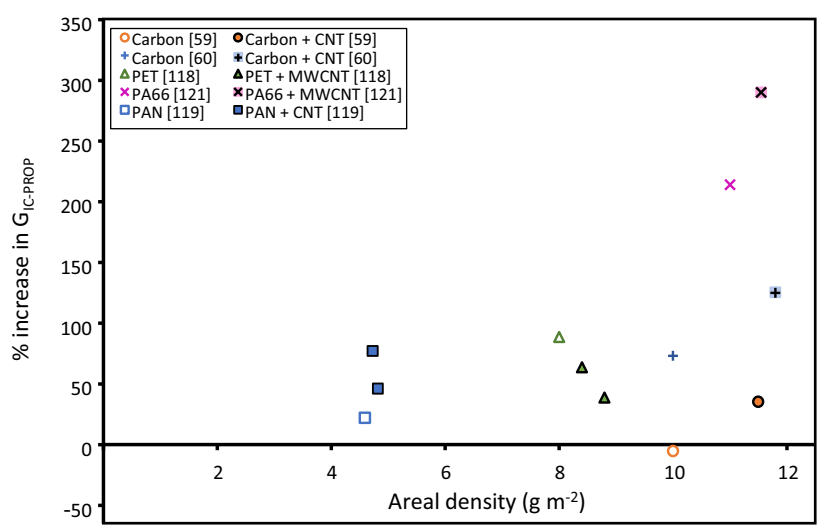

Figure 5 Percentage increase in $\mathrm{G}_{\mathrm{IC}}$ from a non-interleaved control for studies using a veil interleaf combined with CNTs; data from literature, as denoted by reference numbers in the legend. 
$5 \%$, but increased mode II by $200 \%$. They concluded that the CNTs made the carbon veil surface rougher, increasing the strength of the bond between the epoxy and carbon veil fibres. They found evidence also of CNT pull-out from the resin and fracturing of the carbon fibres. These mechanisms resulted in higher energy absorption during crack propagation compared to both the corresponding interleaf without CNTs and a non-interleaved composite. Figure 5 collects data from Lee et al. [59] and other studies reporting the effect of adding CNTs to a nonwoven or electrospun veil.

The addition of CNTs has little effect on the areal density of the veil, but can significantly increase coverage. Most of the data in Fig. 5 show an increase in mode I IFT with the addition of CNTs to the veil, with the exception of the MWCNT-doped PET veils reported by Quan et al. [118]. They considered that in their system, the MWCNTs obstructed fibre bridging of the polymer veil, this mechanism being responsible for the toughening of the non-doped interleaf. The enhanced adhesion between the PET and epoxy matrix that they attribute to the MWCNTs, although beneficial, was insufficient to overcome the decrease in fracture toughness caused by the prevention of fibre bridging. For completeness, we note that Quan et al. [118] report an increase in electrical conductivity when CNTs are incorporated in the interleaf, as anticipated; this has potential implications for multifunctional composites optimising, e.g. toughness and EMI shielding properties. We discuss this further shortly.

Lyashenko-Miller et al. [54] used an interleaf consisting of CNT-enhanced epoxy film in a carbon/ epoxy laminate. The CNTs were treated with SP1 protein which acted as a coupling agent for the CNT and carbon fibre, with the objective of improving adhesion between the carbon and epoxy. They found the toughening depended on the loading rate and crack velocity, where they saw increases of up to $145 \%$ for mode II under the dynamic loading conditions of a cracked lap shear test. Both cohesive failure and interfacial failure occurred, emphasising the importance of the latter to enable bridging of CNTs, which they describe as being the main energy absorption mechanism. Similarly, Rodríguez-González and Rubio-González [117] observed evidence of bridging and pull-out of the CNTs in their investigation of sprayed MWCNTs as interleaves in carbon fibre/epoxy composites. They found the greatest increase $(17 \%)$ in mode II IFT was observed at $0.05 \%$ wt of MWCNTs and attributed this to stronger interfacial bonding due to the functional groups on the MWCNTs. Higher levels of MWCNT addition decreased the fracture toughness, and this was attributed to agglomeration.

$\mathrm{Ou}$ et al. [66] manufactured CNT veils by depositing CNTs directly onto carbon fabric by drawing them from the gas-phase. The interleaved composites showed an increase in mode I fracture toughness of $60 \%$, which was attributed to the crack front alternating between propagating above and below the CNT layer, dissipating crack energy in the process. This observation is consistent with our earlier discussion of optimising interleaf architecture to constrain the propagating crack path within the interleaf. Ou et al. [66] conclude that the densification method of the CNT veil is critical to this optimisation, since a denser veil can act as a defect. Compaction of a dry veil by, e.g. vacuum infusion, results in lower density than densification by capillary-induced solvent action.

Eskizeybek et al. [119] studied hybrid CNT-PAN nanofibre veils, where the CNTs were dispersed in the polymer solution prior to electrospinning, and hence integrated within the nanofibres of the resulting veil. Without $\mathrm{CNTs}$, the interleaf gave a limited increase in $G_{\text {IC-PROP }}$ and a small decrease in G IC-INI. $_{\text {. }}$. The addition of $3 \%$ wt CNT to the PAN interleaf, however, gave increases of $45 \%$ in $G_{\text {IC-PROP }}$ compared to PAN-only and about $80 \%$ higher than the control. A higher percentage of $5 \%$ wt CNTs gave less of an increase in $G_{\text {IC-PROP }}$ than the 3\% CNT, which the authors attributed to agglomeration of CNTs, resulting in beading within the PAN nanofibre network. The hybrid interleaf benefitted from a combination of toughening mechanisms: crack deflection and bridging, pull-out, and breakage of PAN nanofibres, as well as CNT bridging and pull-out.

Nistal et al. [120] investigated several diamine chemical modifications for CNT veils interleaved within composite laminates. Some diamines had a negative effect on the mode I IFT of the composite, though an ethylenediamine-functionalised multilayer CNT veil with areal density of $0.2 \mathrm{~g} \mathrm{~m}^{-2}$ increased $G_{\text {IC }}$ by $13 \%$; from Eq. (1), we estimate that the mean coverage of CNTs in this system was about 3. Hamer et al. [121] interleaved PA66 nanofibres reinforced with MWCNTs within carbon/epoxy laminates and found that the hybrid MWCNT-nanofibre veil 
quadrupled mode I, and increased mode II by $60 \%$. Song et al. [122] carried out a similar study, also using PA66 nanofibres and CNTs for interleaving. They point out that their technique differs from that of Hamer et al., whose CNTs were embedded within PA66 nanofibres by being added to the electrospinning solution. Song et al. suggest that this is less effective since CNTs can aggregate and also limit CNT pull-out and bridging, and that it is more beneficial to have CNTs applied to the fibre surface instead. Although the hybrid interleaves used by Hamer et al. did result in a large increase in IFT, particularly for mode I, the majority of that increase was attributable to the nanofibre base veil which, when used without CNTs, trebled $G_{\text {IC-PROP }}$ and increased $\mathrm{G}_{\text {IIC }}$ by $40 \%$.

To summarise, the main toughening mechanisms identified for CNTs in interleaves include increased interfacial bonding [59, 117, 118], CNT pull-out $[59,117,123]$ and bridging of CNTs [54, 117], the latter two being frequently identified as the toughening mechanisms for nonwoven microfibre veil interleaves also. The addition of CNTs to a nonwoven or electrospun veil is generally found to increase adhesion between the veil and matrix [59, 118, 122], though the contrasting observation of Quan et al. [118] that they could inhibit fibre bridging is noteworthy. Functionalisation of CNT interleaves can improve toughening [120], though the choice of chemical modification is important, as some treatments can cause a reduction in fracture toughness. Since CNTs tend to agglomerate, the manufacturing process, particularly for industrial scaled up use, may need to be optimised to ensure good dispersion [15].

\section{Multifunctionality}

Whilst our focus here is the use of interleaves for toughening of composite laminates, for completeness, we note the potential of interleaves to deliver multifunctionality, i.e. to enhance composite properties beyond improving mechanical properties. Examples include the ability to self-heal defects, to harvest and store energy, and to increase electrical conductivity [124]. Although achieving all of these additional functionalities through interleaving alone is unlikely, interleaves provide a cheap and simple addition to a composite lay-up with proven ability to increase fracture toughness and are excellent candidate materials to deliver nanofibres or nanoparticles to precise locations within the composite.

Some properties enabled through multifunctionality of composites are inherent to metallic alternatives; electrical and thermal conductivity, flammability and impermeability to liquids or gasses [125]. Traditional composites, although possessing other significantly beneficial properties (high stiffness and strength-toweight ratio), cannot compete with the conductivity of metals. Multifunctionality of composites is reviewed elsewhere [126], so discussion here is limited to the use of interleaves to deliver multifunctionality to composite laminates.

\section{Electrical conductivity}

CFRPs typically have low conductivity in the through-thickness direction. In order to provide EMI shielding and lightning strike protection, composites in an airframe typically include a metal mesh to increase electrical conductivity [127]; the addition of polymer interleaves may reduce the conductivity of a CFRP laminate [128]. Accordingly, one class of multifunctionality attracting the attention of researchers is the simultaneous improvement of IFT and electrical conductivity in composite laminates. Methods for improving electrical conductivity of CFRPs and how these affect mechanical properties are reviewed by Brown et al. [129]. Approaches include resin modifications, i.e. incorporating conductive fillers within liquid resin prior to infusion, fibre surface modification, e.g. growth of CNTs onto carbon fibre [130], and interleaving techniques which may incorporate metals or CNTs onto a veil, as discussed earlier.

Several treatments to yield electrical conductivity have been investigated. Barjasteh et al. [128] investigated the fracture toughness and conductivity of composites interleaved with a PA nonwoven veil with a 'graphene/graphite' coating. Compared to the non-interleaved composite, they observed an increase in mode I fracture toughness of $40 \%$ and mode II of $140 \%$, coupled with a decrease in volume resistivity from $100 \mathrm{M} \Omega \mathrm{m}$ to $400 \Omega \mathrm{m}$. Veils with areal density $6 \mathrm{~g} \mathrm{~m}^{-2}$ and $12 \mathrm{~g} \mathrm{~m}^{-2}$ were tested, with the latter giving the lowest resistivity; only the $12 \mathrm{~g} \mathrm{~m}^{-2}$ was tested for fracture toughness. Guo et al. [131] used a $16 \mathrm{~g} \mathrm{~m}^{-2}$ nonwoven nylon veil that had been immersed in a suspension of silver nanowires (AgNWs) prior to being interleaved in carbon/epoxy prepreg laminates. When tested under mode I and 
mode II loading, these composites exhibited increases in $G_{C}$ of $120 \%$ and $230 \%$, respectively, whilst in-plane conductivity increased by over $100 \times$, and throughthickness conductivity increased by $10 \times$. Guo et al [132] investigated silver-plated interleaves using nylon and Kevlar veils coated by electroless silver plating; both exhibited increased conductivity as interleaves in a prepreg laminate. Although both Agplated veil interleaves increased $G_{\text {IC }}$ and $G_{\text {IIC }}$, these increases were slightly lower than for the non-Agplated veils; this was attributed to weak interfacial bonding between the silver-plated surface and the carbon fibre and/or resin. Similarly, Hu et al. [8] used electroless copper-nickel-plated polyester veil interleaves and observed increases of GIC-INI $_{\text {of around }}$ $70 \%$ and of $G_{\text {IC-PROP }}$ by $40 \%$, coupled with a large increase in the conductivity of the composite.

Coating or plating with metal films is not the only way to increase electrical conductivity of veil interleaves. Carbon is a relatively good electrical conductor and can be incorporated into an interleaf in various forms, including CNTs, as discussed previously. Quan et al. [118] improved the conductivity of carbon/epoxy composites using MWCNT-doped PET veils, although the increase in fracture toughness was less than when using an non-doped veil. Li et al. [133] also used MWCNTs doped onto a polyurethane film. They found that both the electrical conductivity and the mode II fracture toughness were increased, by around $13 \%$ and $100 \%$, respectively. They note that although a larger increase in fracture toughness using silver nanowires was observed by Guo et al. [131], the through-thickness conductivity for the MWCNT-doped interleaf was greater. Li et al. [133] noted also that CNTs are cheaper than silver nanowires, bringing an important perspective to the selection of materials for optimisation of multifunctional interleaves.

Wang et al. [134] loaded polypropylene nonwoven interleaves with carbon black to increase their conductivity. The mode I IFT increased for both initial $G_{I C}$ and propagation $G_{I C}$ by $90 \%$ and $130 \%$, respectively. Although the carbon black treatment mitigated the decrease in through-thickness conductivity caused by the insulating PP interleaf, it did not yield any further improvement.

We have seen that several studies report improvements in both electrical conductivity and fracture toughness, though Brown et al. [129] reasoned that some methods used to increase conductivity are not scalable to industrial level, since they either produce a viscous resin, such as the CNT modification of epoxy [135] or use methods which are too complex, such as a plasma treated CNT film interleaf [136]. Nonetheless, developments of scalable technologies that build upon these proof-of-concept studies are likely in the evolution of lightweighting strategies for aircraft structures.

\section{Energy storage}

Technologies to reduce fuel and energy consumption in the aerospace and automotive sectors by storing energy within composite structures have been investigated [137]. The multifunctionality sought here is the integration of energy harvesting and storage systems in composites with improved mechanical performance. Although technologies such as structural dielectric capacitors store less energy than batteries, the layers of carbon fibre in a laminate provide ample surface area to enable integration of a large capacitor whilst saving space [138]. The review of Chan et al. [137] provides an in-depth discussion of various dielectric capacitors integrated into multifunctional composites and their performance, and that of $\mathrm{Xu}$ et al. [139] examines the advances in structural supercapacitor composites, including their fabrication and performance characterisation. We direct the interested reader to these contributions, but for completeness provide here a very brief oversight of how interleaves can enable energy storage within composite structures.

In order to create a capacitor within a composite, materials can be embedded within the laminate layers through interleaving. This can include the addition of carbon fibre electrodes, polymer electrolytes and separators [139]. Senokos et al. [140] investigated the use of CNT fibre veils combined with ionic liquidbased polymer electrolytes placed between carbon fabric plies. As we have discussed, CNT veils on their own can increase fracture toughness; however, when used as a part of a capacitor, Senokos et al. [140] found that the soft polymer electrolyte interleaf can act as a defect, increasing delamination. To mitigate this effect, they designed a supercapacitor interleaf with a grid structure, allowing epoxy to pass through and connect between the layers, as observed via 3D tomography.

Sun et al. [141] investigated the combination of Kevlar/epoxy prepreg laminates with a carbon 
fibre/solid-electrolyte interleaf as a supercapacitor, concluding that the interleaf could provide superior electrochemical performance. They also suggested that further research should explore the use of CNTbased continuous fibres as electrodes, utilising their high specific surface area.

Imparting multifunctionality to composites without compromising other properties is clearly a challenging task. Simultaneous improvement in multiple functions is often accompanied by complex processing methods, which may not yet be scalable to industrial levels. Despite this, the potential benefits of multifunctionality for aerospace, automotive and many other industries are providing a strong driver for further work in this area. The review of González et al. [125] explores the current challenges and future trends of multifunctional composites, focussing on 3 areas: manufacturing techniques, multi-scale design strategies and the integration of additional functionalities. They conclude that improvements in all 3 areas will enable composites to be used in more diverse application areas and suggest that additional functions such as energy harvesting and storage will be the focus of future developments.

\section{Commercial viability}

Given the substantial scientific literature describing the use of nonwoven interleaves for toughening of composites, we sought to identify literature describing commercial application of these technologies. It seems that these are limited: we have found one example of commercial use of nanofibre veils [102] for increasing fracture toughness of laminated composites and one of microfibre veils [142]. We identified also a patent for a composite system which includes a CNT/carbon veil for increasing electrical conductivity [143]. Despite commercial availability of interleaves for composites, significant research and development of these materials continues, highlighting the need for further refinement. The low cost of nonwovens manufacture, coupled with the significant potential for performance improvement with low weight penalty makes nonwoven interleaves attractive to the aerospace and automotive industries. Associated costs and complexity of manufacture could prevent some interleaves from being commercialised. There are a range of considerations when assessing the scalability of an interleaving system, such as raw material availability, cost of resources and processing, compatibility with the composite manufacturing method, including resin compatibility and interleaf handle-ability.

Meireman et al. [107] claim that their electrospinning method enables industrial scale-up of manufacturing electrospun interleaves. They suggest that the main obstacle is polymer choice, taking into account considerations that we have discussed earlier such as quality of adhesion to the matrix, melting point, etc.

Although imparting additional functionality to a material system usually involves adding materials, coatings or treatments, which all increase the cost and complexity of manufacture, the resulting multifunctional composite could lead to post-production costs being reduced [126]. Hybrid veils have the potential to deliver multifunctionality, possibly avoiding additional steps in processing, and hence cost. Although cost is usually an important factor when designing composite structures, significant enhancement of composite properties could justify higher cost of materials and processing, especially for very high performance structures.

\section{Design strategy: materials systems for interleaves}

We have seen that there are many variables to consider when evaluating which type of interleaf is most suitable for a particular purpose. Choice of fibre type will depend on whether the interleaf is required for interlaminar toughening only, or if other functionalities need to be incorporated. For example, a nonwoven veil made from a polymer such as PPS at relatively high areal density, around $40 \mathrm{~g} \mathrm{~m}^{-2}$, can achieve significant increases in IFT [36]. If lowering the weight and thickness of the interleaf is important, then electrospun nanofibre veils may be suitable, but the almost negligible effect on weight may come at the expense of IFT- only small increases, around $40 \%$ may be achieved. If electrical conductivity is required, then a polymer interleaf would need to be coated or treated with a conductive material, e.g. silver nanowires, CNTs or metal-plating, increasing cost and complexity of manufacture.

A common issue for interleaved composites under mode I and mode II loading is the crack moving out of the interleaf and along the matrix at the interface, 


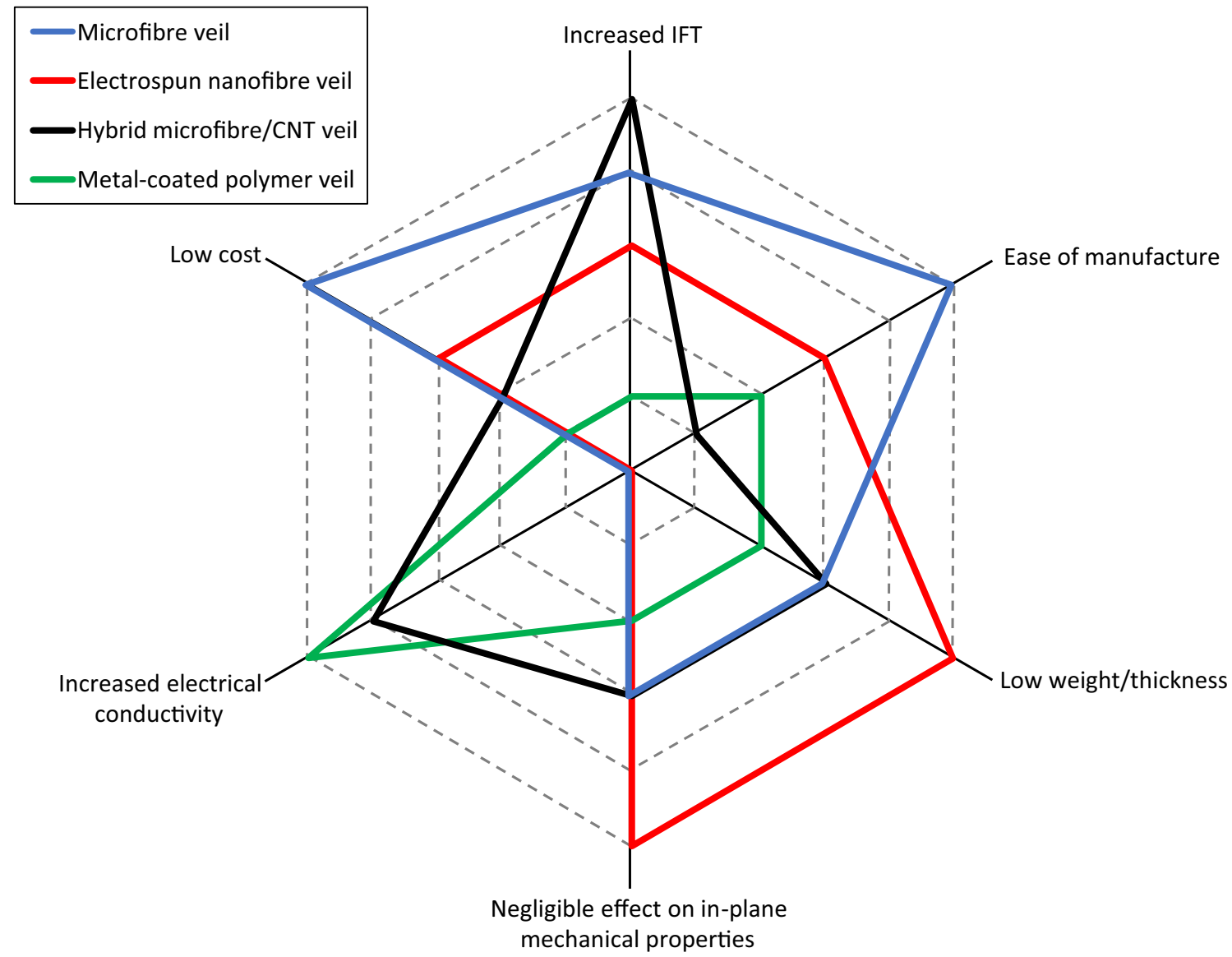

Figure 6 Radar plot comparing four main veil types: microfibre, nanofibre, hybrid microfibre/CNT and metal-coated polymer, ranked according to five main attributes for successful interleaves.

along the path of least resistance. We note that Daelemans et al. [106] observed the crack path to undergo several interlaminar crossings, providing good dissipation of fracture energy. Many studies conclude that a strong bond between the veil and the matrix helps to increase IFT; poor adhesion between interleaf and matrix results in the crack propagating along the interface, leading to adhesive failure [75]. Recalling from our discussion of Figs. 3 and 4, it seems there is a surprisingly low sensitivity to veil polymer/fibre type on the increase of IFT observed for microfibre interleaves. Of course, those data were collected from independent studies; in more controlled contexts, opportunities persist to optimise performance through consideration of an interleaf's ability to form a strong bond with the matrix, melting point, commercial availability, cost, and compatibility with electrospinning process, if using nanofibres. Figure 6 shows a comparison of 4 main interleaf types: microfibre veils, nanofibre veils, hybrid
microfibre/CNT veils and metal-coated polymer veils, which we have scored according to six primary attributes of interleaves. Of course, this is at best a semi-quantitative approach, though we have sought to be objective in our rankings, with the intention of summarising the main dependencies observed in this review to guide materials selection. For example, if high IFT is the most important feature, a microfibre veil arguably has advantages over other candidate interleaves, but comes with a weight penalty; whereas if conductivity is imperative, then either a $\mathrm{CNT}$ or metal-coated veil is required. Inevitably, compromise is necessary; currently, no material system identified possesses all of the ideal attributes.

\section{Conclusions}

We have reviewed the literature describing the potential for various materials to be used as interleaves to toughen interlaminar regions in fibre- 
reinforced polymer composites. Much recent research has focussed on nanofibres and CNTs, though we find that superior toughening is often obtained with nonwoven microfibre veils, with hybrid systems of these coupled with nanomaterials offering pathways to multifunctionality.

Use of nanotechnology brings benefits, but increases complexity and cost also. Further, the highest reported increases in $G_{I C}$ from nanofibre interleaving studies often arise from data from initiation of the crack only, or by discounting data recorded once the crack has moved away from the interleaf. To understand the difference between the toughening potential of nanofibre and microfibre interleaves, we calculated the mean coverage of interleaves from data reported in the literature. We found that nanofibre interleaves, despite having lower or comparable areal densities to microfibre interleaves, exhibited high coverage; this is associated with a low open area and small pore size, potentially reducing the extent of resin infusion during composite manufacture. Invariably, we found that microfibre veils used in interleaving research had mean coverage less than 5, such that infusion should be more effective. Further, for these fibres, the results from several studies were closely clustered and showed a more systematic dependence of toughening on coverage that showed only a weak influence of fibre type.

Perhaps unsurprisingly, effective toughening from either nanofibre or microfibre interleaves depends on the same properties: good adhesion between the nanofibres and the polymer matrix is essential for energy consumed by fibre pull-out and fibre bridging to be maximised. A challenge in optimising interleaf performance is retaining the propagating crack within the reinforced region. We have seen some evidence that this might, in part, be aided by inclusion of CNTs within an interleaf, which bring opportunities for multifunctionality also; equally, negative effects on toughening from inclusion of CNTs within interleaves have been reported. Where CNTs have been delivered to a reinforcement zone by spraying, their tendency to agglomerate has been found to reduce their effectiveness. Incorporation of CNTs within a nonwoven veil offers one pathway to maximising their dispersion, though it is clear that more work is required for the potential of hybrid interleaves to increase toughness to be realised.

We closed our review with an assessment of the commercial uptake of fibrous interleaving systems for interlaminar toughening followed by a brief overview of preliminary considerations for a design strategy to incorporate these in composites. The latter revealed the extent to which competing performance objectives may require compromise or multi-component materials systems. Over the coming years, we anticipate that engineering approaches to facilitate these will deliver broader commercial implementation of fibrous interleave technologies.

\section{Acknowledgements}

We gratefully acknowledge the financial support of the EPSRC and Technical Fibre Products Ltd., Kendal, UK, for Nicola Vallack's doctoral studies under the CASE Award scheme.

\section{Declarations}

Conflict of interest The authors declare that they have no conflict of interest.

Open Access This article is licensed under a Creative Commons Attribution 4.0 International License, which permits use, sharing, adaptation, distribution and reproduction in any medium or format, as long as you give appropriate credit to the original author(s) and the source, provide a link to the Creative Commons licence, and indicate if changes were made. The images or other third party material in this article are included in the article's Creative Commons licence, unless indicated otherwise in a credit line to the material. If material is not included in the article's Creative Commons licence and your intended use is not permitted by statutory regulation or exceeds the permitted use, you will need to obtain permission directly from the copyright holder. To view a copy of this licence, visit http://creativecommons.org/licen ses/by/4.0/.

\section{References}

[1] Gibson RF (2011) Principles of composite materials mechanics, 3rd edn. Taylor \& Francis, CRC Press, Boca Raton

[2] Baharozu E, Soykan G, Ozerdem MB (2017) Future aircraft concept in terms of energy efficiency and environmental factors. Energy 140:1368-1377. https://doi.org/10.1016/j.e nergy.2017.09.007 
[3] Gheryani AA, Fleming DC, Reichard RP (2019) Nonwoven polyester interleaving for toughness enhancement in composites. J Compos Mater 53:4349-4367. https://doi.or g/10.1177/0021998319857116

[4] Thomas R, Yumei D, Yuelong H et al (2008) Miscibility, morphology, thermal, and mechanical properties of a DGEBA based epoxy resin toughened with a liquid rubber. Polymer (Guildford) 49:278-294. https://doi.org/10.1016/j. polymer.2007.11.030

[5] MacKinnon AJ, Pethrick RA, Jenkins SD, McGrail PT (1992) A dielectric, mechanical, rheological and electron microscopy study of cure and properties of a thermoplasticmodified epoxy resin. Macromolecules 25:3492-3499. h ttps://doi.org/10.1021/ma00039a029

[6] Bucknall CB, Gilbert AH (1989) Toughening tetrafunctional epoxy resins using polyetherimide. Polymer (Guildford) 30:213-217. https://doi.org/10.1016/00323861(89)90107-9

[7] Wong DWY, Zhang H, Bilotti E, Peijs T (2017) Interlaminar toughening of woven fabric carbon/epoxy composite laminates using hybrid aramid/phenoxy interleaves. Compos Part A Appl Sci Manuf 101:151-159. https://doi.org/ 10.1016/j.compositesa.2017.06.001

[8] Hu D, Yi X, Jiang M et al (2020) Development of highly electrically conductive composites for aeronautical applications utilizing bi-functional composite interleaves. Aerosp Sci Technol 98:105669. https://doi.org/10.1016/j.a st.2019.105669

[9] Gardiner G (2015) Aerocomposites: the move to multifunctionality. Composites World, November 2015, pp 42-48

[10] Shivakumar K, Panduranga R (2013) Interleaved polymer matrix composites - a review. In: 54th AIAA/ASME/ ASCE/AHS/ASC structures, structural dynamics, and materials conference. https://doi.org/10.2514/6.2013-1903

[11] Tsotsis TK (2009) Interlayer toughening of composite materials. Polym Compos 30:70-86. https://doi.org/10.10 02/pc. 20535

[12] TFP Ltd, James Cropper PLC (2021) Composite materials. https://www.tfpglobal.com/products/composite-materials. Accessed 1 Mar 2021

[13] Cheng C, Zhang C, Zhou J et al (2019) Improving the interlaminar toughness of the carbon fiber/epoxy composites via interleaved with polyethersulfone porous films. Compos Sci Technol. https://doi.org/10.1016/j.compscitec h.2019.107827

[14] Shrivastava R, Singh KK (2019) Interlaminar fracture toughness characterization of laminated composites: a review. Polym Rev. https://doi.org/10.1080/15583724.201 9.1677708
[15] Di BY, Joshi SC (2020) A review of methods for improving interlaminar interfaces and fracture toughness of laminated composites. Mater Today Commun. https://doi.org/10.101 6/j.mtcomm.2019.100830

[16] Dikshit V, Bhudolia SK, Joshi SC (2017) Multiscale polymer composites: a review of the interlaminar fracture toughness improvement. Fibers. https://doi.org/10.3390/fib 5040038

[17] Shakil UA, Hassan SBA, Yahya MY, Nauman S (2020) Mechanical properties of electrospun nanofiber reinforced/ interleaved epoxy matrix composites - a review. Polym Compos. https://doi.org/10.1002/pc.25539

[18] Palazzetti R, Zucchelli A (2017) Electrospun nanofibers as reinforcement for composite laminates materials - a review. Compos Struct 182:711-727

[19] Vasiliev VV, Morozov EV (2007) Advanced mechanics of composite materials, 2nd edn. Elsevier, Amsterdam

[20] Hull D, Clyne TW (1996) An introduction to composite materials, 2nd edn. Cambridge University Press, Cambridge

[21] Harris B (1999) Engineering composite materials, 2nd edn. IOM, London

[22] Yi X-S, Friedrich K, Breuer U (2015) Development of multifunctional composites for aerospace application. Multifunctionality of polymer composites. Elsevier, Amsterdam, pp 367-418

[23] Giurgiutiu V (2016) Introduction. Structural health monitoring of aerospace composites. Academic Press, Cambridge, pp 1-23

[24] Daelemans L, Van Paepegem W, De Clerck K (2020) Effect of interleaved polymer nanofibers on the properties of glass and carbon fiber composites. Fiber-reinforced nanocomposites: fundamentals and applications. Elsevier, Amsterdam, pp 235-260

[25] Fazelzadeh SA, Mazidi A, Kalantari H (2009) Bendingtorsional flutter of wings with an attached mass subjected to a follower force. J Sound Vib 323:148-162. https://doi.org/ 10.1016/j.jsv.2009.01.002

[26] Herakovich CT (1998) Mechanics of fibrous composites. Wiley, New York

[27] Brunner AJ (2020) Fracture mechanics of polymer composites in aerospace applications. Polymer composites in the aerospace industry. Woodhead Publishing, Duxford, pp 195-252

[28] Griffith AA (1921) The phenomena of rupture and flow in solids. Philos Trans R Soc Lond Ser A Contain Pap Math Phys Character 221:163-198. https://doi.org/10.1098/rsta. 1921.0006 
[29] Irwin GR (1948) Fracture dynamics. Fracturing of metals. In: ASM-symposium, 1947, American society for metals, pp 147-166

[30] Orowan E (1949) Fracture and strength of solids. Rep Prog Phys 12:185-232

[31] Park SJ, Seo MK (2011) Solid-solid interfaces. Interface Sci Technol 18:253-331. https://doi.org/10.1016/B978-0-1 2-375049-5.00004-9

[32] Nasuha N, Azmi AI, Tan CL (2017) A review on mode-I interlaminar fracture toughness of fibre reinforced composites. J Phys Conf Ser. https://doi.org/10.1088/1742-659 6/908/1/012024

[33] Mouritz AP (2012) Fracture processes of aerospace materials. Introduction to aerospace materials. Woodhead, Cambridge, pp 428-453

[34] Nijssen RPL (2015) Composite materials an introduction. VKCN, Leidschendam

[35] Peters ST (1998) Handbook of composites, 2nd edn. Chapman \& Hall, London

[36] Ramirez VA, Hogg PJ, Sampson WW (2015) The influence of the nonwoven veil architectures on interlaminar fracture toughness of interleaved composites. Compos Sci Technol 110:103-110. https://doi.org/10.1016/j.compscitech.2015.0 1.016

[37] Robinson P, Hodgkinson JM (2000) Interlaminar fracture toughness. In: Hodgkinson JM (ed) Mechanical testing of advanced fibre composites. Woodhead, Cambridge, pp 170-210

[38] Laffan MJ (2012) Testing the toughness of polymer matrix composites. Fail Mech Polym Matrix Compos Criteria Test Ind Appl. https://doi.org/10.1016/B978-1-84569-750-1.50 005-7

[39] Arrese A, Mujika F (2008) Influence of bending rotations on three and four-point bend end notched flexure tests. Eng Fract Mech 75:4234-4246. https://doi.org/10.1016/j.engfra cmech.2008.03.012

[40] Kuwata M, Hogg PJ (2011) Interlaminar toughness of interleaved CFRP using non-woven veils: part 2. Mode-II testing. Compos Part A Appl Sci Manuf 42:1560-1570. h ttps://doi.org/10.1016/j.compositesa.2011.07.017

[41] Davies P, Casari P, Carlsson LA (2005) Influence of fibre volume fraction on mode II interlaminar fracture toughness of glass/epoxy using the 4ENF specimen. Compos Sci Technol 65:295-300. https://doi.org/10.1016/j.compscitec h.2004.07.014

[42] Wang WX, Nakata M, Takao Y, Matsubara T (2009) Experimental investigation on test methods for mode II interlaminar fracture testing of carbon fiber reinforced composites. Compos Part A Appl Sci Manuf
40:1447-1455. https://doi.org/10.1016/j.compositesa.2009. 04.029

[43] Martin RH, Davidson BD (1999) Mode II fracture toughness evaluation using four point bend, end notched flexure test. Plast Rubber Compos Process Appl 28:401-406. h ttps://doi.org/10.1179/146580199101540565

[44] Adams DF, Whitney TJ (2018) Test methods for mechanical properties. Compr Compos Mater II 7:4-37. https://doi. org/10.1016/B978-0-12-803581-8.10032-3

[45] Beckermann GW, Pickering KL (2015) Mode I and mode II interlaminar fracture toughness of composite laminates interleaved with electrospun nanofibre veils. Compos Part A Appl Sci Manuf 72:11-21. https://doi.org/10.1016/j.co mpositesa.2015.01.028

[46] İnal O, Akbolat MÇ, Soutis C, Katnam KB (2021) Toughening mechanisms in cost-effective carbon-epoxy laminates with thermoplastic veils: mode-I and in-situ SEM fracture characterisation. Int J Lightweight Mater Manuf 4:50-61. https://doi.org/10.1016/j.ijlmm.2020.07.003

[47] García-Rodríguez SM, Costa J, Rankin KE et al (2020) Interleaving light veils to minimise the trade-off between mode-I interlaminar fracture toughness and in-plane properties. Compos Part A Appl Sci Manuf. https://doi.org/10. 1016/j.compositesa.2019.105659

[48] ASTM D5528-13 (2013) Standard test method for mode I interlaminar fracture toughness of unidirectional fiber-reinforced polymer matrix composites

[49] Miller RJ (2000) Design approaches for high temperature composite aeroengine components. Compr Compos Mater 6:181-207. https://doi.org/10.1016/b0-08-042993-9/001388

[50] Saba N, Jawaid M, Sultan MTH (2019) An overview of mechanical and physical testing of composite materials. Mech Phys Test Biocomposites Fibre-Reinf Compos Hybrid Compos. https://doi.org/10.1016/B978-0-08-10229 2-4.00001-1

[51] Hancox NL (2000) An overview of the impact behaviour of fibre-reinforced composites. Impact behaviour of fibre-reinforced composite materials and structures. Woodhead, Cambridge, pp 1-32

[52] Cantwell WJ, Morton J (1991) The impact resistance of composite materials - a review. Composites 22:347-362. h ttps://doi.org/10.1016/0010-4361(91)90549-V

[53] Bouvet C, Rivallant S (2016) Damage tolerance of composite structures under low-velocity impact. Dyn Deform Damage Fract Compos Mater Struct. https://doi.org/10.10 16/b978-0-08-100080-9.00002-6

[54] Lyashenko-Miller T, Fitoussi J, Marom G (2016) The loading rate effect on mode II fracture toughness of 
composites interleaved with CNT. Nanocomposites 2:1-7. https://doi.org/10.1080/20550324.2016.1159372

[55] Hogg PJ, Bibo GA (2000) Impact and damage tolerance. In: Hodgkinson JM (ed) Mechanical testing of advanced fibre composites. Woodhead, Cambridge, pp 211-247

[56] Masters JE (1989) Improved impact and delamination resistance through interleafing. Key Eng Mater 37:317. h ttps://doi.org/10.4028/www.scientific.net/kem.37.317

[57] Yuan B, Tan B, Hu Y et al (2019) Improving impact resistance and residual compressive strength of carbon fibre composites using un-bonded non-woven short aramid fibre veil. Compos Part A Appl Sci Manuf 121:439-448. http s://doi.org/10.1016/j.compositesa.2019.04.006

[58] Beckermann GW (2017) Nanofiber interleaving veils for improving the performance of composite laminates. Reinf Plast 61:289-293. https://doi.org/10.1016/j.repl.2017.03. 006

[59] Lee SH, Kim H, Hang S, Cheong SK (2012) Interlaminar fracture toughness of composite laminates with CNT-enhanced nonwoven carbon tissue interleave. Compos Sci Technol 73:1-8. https://doi.org/10.1016/j.compscitech.201 2.09.011

[60] Zhou H, Du X, Liu HY et al (2017) Delamination toughening of carbon fiber/epoxy laminates by hierarchical carbon nanotube-short carbon fiber interleaves. Compos Sci Technol 140:46-53. https://doi.org/10.1016/j.compscitech. 2016.12.018

[61] Yun NG, Won YG, Kim SC (2004) Toughening of carbon fiber/epoxy composite by inserting polysulfone film to form morphology spectrum. Polymer (Guildford) 45:6953-6958. https://doi.org/10.1016/j.polymer.2004.08.020

[62] Yao J, Niu K, Niu Y, Zhang T (2019) Toughening efficiency and mechanism of carbon fibre epoxy matrix composites by PEK-C. Compos Struct 229:111431. https://doi. org/10.1016/j.compstruct.2019.111431

[63] Aksoy A, Carlsson LA (1992) Interlaminar shear fracture of interleaved graphite/epoxy composites. Compos Sci Technol. https://doi.org/10.1016/0266-3538(92)90133-N

[64] Guo M, Liu L (2019) Structuring the thermoplastic interleaf with lotus-leaf-like structure and its interlaminar toughening for CFRPs. Compos Sci Technol 183:107825. https://d oi.org/10.1016/j.compscitech.2019.107825

[65] van der Heijden S, Daelemans L, Meireman T et al (2016) Interlaminar toughening of resin transfer molded laminates by electrospun polycaprolactone structures: effect of the interleave morphology. Compos Sci Technol 136:10-17. h ttps://doi.org/10.1016/j.compscitech.2016.09.024

[66] Ou Y, González C, Vilatela JJ (2019) Interlaminar toughening in structural carbon fiber/epoxy composites interleaved with carbon nanotube veils. Compos Part A Appl
Sci Manuf 124:105477. https://doi.org/10.1016/j.composite sa.2019.105477

[67] Wilson A (2010) The formation of dry, wet, spunlaid and other types of nonwovens. Appl Nonwovens Tech Text. $h$ ttps://doi.org/10.1016/B978-1-84569-437-1.50001-X

[68] Sampson WW (2008) Modelling stochastic fibrous materials with mathematica. Springer, London

[69] Hirschbuehler KR, Stern BA, American Cyanamid Co. (1985) High impact strength fiber resin matrix composites 4539253

[70] Kohan MI (1995) Nylon plastics handbook. Hanser/Gardner, Cincinnati

[71] Walker L, Hu XZ (2002) Mode I delamination behaviour of short fibre reinforced carbon fibre/epoxy composites following environment conditioning. Compos Sci Technol. h ttps://doi.org/10.1016/S0266-3538(02)00224-5

[72] Sampson WW, Sirvio J (2005) The Statistics of interfibre contact in random fibre networks. J Pulp Pap Sci 31:127-131

[73] Kuwata M, Hogg PJ (2011) Interlaminar toughness of interleaved CFRP using non-woven veils: part 1. Mode-I testing. Compos Part A Appl Sci Manuf 42:1560-1570. h ttps://doi.org/10.1016/j.compositesa.2011.07.017

[74] Quan D, Bologna F, Scarselli G et al (2019) Interlaminar fracture toughness of aerospace-grade carbon fibre reinforced plastics interleaved with thermoplastic veils. Compos Part A Appl Sci Manuf. https://doi.org/10.1016/j.c ompositesa.2019.105642

[75] Zheng N, Liu HY, Gao J, Mai YW (2019) Synergetic improvement of interlaminar fracture energy in carbon fiber/epoxy composites with nylon nanofiber/polycaprolactone blend interleaves. Compos Part B Eng 171:320-328. https://doi.org/10.1016/j.compositesb.2019.0 5.004

[76] Wong DWY, Lin L, McGrail PT et al (2010) Improved fracture toughness of carbon fibre/epoxy composite laminates using dissolvable thermoplastic fibres. Compos Part A Appl Sci Manuf 41:759-767. https://doi.org/10.1016/j.c ompositesa.2010.02.008

[77] Solvay PRIFORM®. https://www.solvay.com/en/brands/pr iform. Accessed 6 Oct 2021

[78] Zheng W, Yao Z, Lin H et al (2019) Improved fracture toughness of carbon fiber fabric/epoxy composite laminates using polyether sulfone fibers. High Perform Polym 31:996-1005. https://doi.org/10.1177/0954008318812151

[79] Maccaferri E, Mazzocchetti L, Benelli T et al (2020) Rubbery nanofibrous interleaves enhance fracture toughness and damping of CFRP laminates. Mater Des 195:109049. https://doi.org/10.1016/j.matdes.2020.109049 
[80] Cheng C, Chen Z, Huang Z et al (2020) Simultaneously improving mode I and mode II fracture toughness of the carbon fiber/epoxy composite laminates via interleaved with uniformly aligned PES fiber webs. Compos Part A Appl Sci Manuf. https://doi.org/10.1016/j.compositesa.201 9.105696

[81] Lee S-H, Noguchi H, Kim Y, Cheong S (2002) Effect of interleaved non-woven carbon tissue on interlaminar fracture toughness of laminated composites: part II-mode I. J Compos Mater 36:2169-2181. https://doi.org/10.1177/ 0021998302036018980

[82] Lee SH, Noguchi H, Kim YB, Cheong SK (2002) Effect of interleaved non-woven carbon tissue on interlaminar fracture toughness of laminated composites: part I-mode II. J Compos Mater 36:2153-2168. https://doi.org/10.1177/ 0021998302036018981

[83] Sierakowski RL, Newaz GM (1995) Damage tolerance in advanced composites. Technomic Publishing Company, Pennsylvania

[84] Wang X, Lin T (2013) Needleless electrospinning of nanofibers: technology and applications. Pan Stanford Publishing, Singapore

[85] Almetwally AA, El-Sakhawy M, Elshakankery MH, Kasem MH (2017) Technology of nano-fibers: production techniques and properties-critical review. J Text Assoc 78:5-14

[86] Asmatulu R, Khan WS (2019) Introduction to electrospun nanofibers. Synth Appl Electrospun Nanofibers. https://doi. org/10.1016/b978-0-12-813914-1.00001-8

[87] Thenmozhi S, Dharmaraj N, Kadirvelu K, Kim HY (2017) Electrospun nanofibers: new generation materials for advanced applications. Mater Sci Eng B Solid-State Mater Adv Technol 217:36-48. https://doi.org/10.1016/j.mseb.20 17.01.001

[88] Zucchelli A, Focarete ML, Gualandi C, Ramakrishna S (2011) Electrospun nanofibers for enhancing structural performance of composite materials. Polym Adv Technol 22:339-349. https://doi.org/10.1002/pat.1837

[89] Ibrahim HM, Klingner A (2020) A review on electrospun polymeric nanofibers: production parameters and potential applications. Polym Test 90:106647. https://doi.org/10.101 6/j.polymertesting.2020.106647

[90] Khan Z, Kafiah F, Zahid Shafi H et al (2015) Morphology, mechanical properties and surface characteristics of electrospun polyacrylonitrile (PAN) nanofiber mats. Int J Adv Eng Nano Technol 2:2347-6389

[91] Daelemans L, van der Heijden S, De Baere I et al (2015) Nanofibre bridging as a toughening mechanism in carbon/ epoxy composite laminates interleaved with electrospun polyamide nanofibrous veils. Compos Sci Technol
117:244-256. https://doi.org/10.1016/j.compscitech.2015.0 6.021

[92] Beylergil B, Aktas E, Tano M (2017) Enhancement of interlaminar fracture toughness of carbon fiber-epoxy composites using polyamide-6,6 electrospun nanofibers. J Appl Polym Sci 45244:1-12. https://doi.org/10.1002/app. 45244

[93] Magniez K, De Lavigne C, Fox BL (2010) The effects of molecular weight and polymorphism on the fracture and thermo-mechanical properties of a carbon-fibre composite modified by electrospun poly (vinylidene fluoride) membranes. Polymer (Guildford) 51:2585-2596. https://doi.org/ 10.1016/j.polymer.2010.04.021

[94] Huang ZM, Zhang YZ, Kotaki M, Ramakrishna S (2003) A review on polymer nanofibers by electrospinning and their applications in nanocomposites. Compos Sci Technol 63:2223-2253. https://doi.org/10.1016/S0266-3538(03)00 $178-7$

[95] Kim JS, Reneker DH (1999) Mechanical properties of composites using ultrafine electrospun fibers. Polym Compos 20:124-131. https://doi.org/10.1002/pc.10340

[96] Wang G, Yu D, Kelkar AD, Zhang L (2017) Electrospun nanofiber: emerging reinforcing filler in polymer matrix composite materials. Prog Polym Sci 75:73-107

[97] Aljarrah MT, Abdelal NR (2019) Improvement of the mode I interlaminar fracture toughness of carbon fiber composite reinforced with electrospun nylon nanofiber. Compos Part B Eng. https://doi.org/10.1016/j.compositesb.2019.01.065

[98] Daelemans L, van der Heijden S, De Baere I et al (2017) Improved fatigue delamination behaviour of composite laminates with electrospun thermoplastic nanofibrous interleaves using the central cut-ply method. Compos Part A Appl Sci Manuf 94:10-20. https://doi.org/10.1016/j.co mpositesa.2016.12.004

[99] Zhang J, Yang T, Lin T, Wang CH (2012) Phase morphology of nanofibre interlayers: critical factor for toughening carbon/epoxy composites. Compos Sci Technol. h ttps://doi.org/10.1016/j.compscitech.2011.11.010

[100] Saghafi H, Brugo T, Minak G, Zucchelli A (2015) The effect of PVDF nanofibers on mode-I fracture toughness of composite materials. Compos Part B Eng. https://doi.org/ 10.1016/j.compositesb.2014.12.015

[101] Zhang H, Bharti A, Li Z et al (2015) Localized toughening of carbon/epoxy laminates using dissolvable thermoplastic interleaves and electrospun fibres. Compos Part A Appl Sci Manuf. https://doi.org/10.1016/j.compositesa.2015.09.024

[102] NanoLayr (2021) Xantulayr. https://www.nanolayr.com/pr oduct/xantulayr/. Accessed 5 Nov 2021

[103] Zhang J, Lin T, Wang X (2010) Electrospun nanofibre toughened carbon/epoxy composites: effects of 
polyetherketone cardo (PEK-C) nanofibre diameter and interlayer thickness. Compos Sci Technol 70:1660-1666. h ttps://doi.org/10.1016/j.compscitech.2010.06.019

[104] Daelemans L, van der Heijden S, De Baere I et al (2016) Using aligned nanofibres for identifying the toughening micromechanisms in nanofibre interleaved laminates. Compos Sci Technol 124:17-26. https://doi.org/10.1016/j.c ompscitech.2015.11.021

[105] Xia ZC, Hutchinson JW (1994) Mode II fracture toughness of a brittle adhesive layer. Int J Solids Struct 31:1133-1148. https://doi.org/10.1016/0020-7683(94)90168-6

[106] Daelemans L, Van Der Heijden S, De Baere I et al (2016) Damage-resistant composites using electrospun nanofibers: a multiscale analysis of the toughening mechanisms. ACS Appl Mater Interfaces 8:11806-11818. https://doi.org/10. 1021/acsami.6b02247

[107] Meireman T, Daelemans L, Rijckaert S et al (2020) Delamination resistant composites by interleaving biobased long-chain polyamide nanofibers through optimal control of fiber diameter and fiber morphology. Compos Sci Technol 193:108126. https://doi.org/10.1016/j.compscitec h. 2020.108126

[108] Greiner A, Wendorff JH (2007) Electrospinning: a fascinating method for the preparation of ultrathin fibers. Angew Chemie Int Ed 46:5670-5703. https://doi.org/10.1002/anie. 200604646

[109] Chen L, Wu LW, Jiang Q et al (2019) Improving interlaminar fracture toughness and impact performance of carbon fiber/epoxy laminated composite by using thermoplastic fibers. Molecules. https://doi.org/10.3390/molecule s24183367

[110] Beylergil B, Tanoğlu M, Aktaş E (2018) Effect of polyamide-6, 6 (PA 66) nonwoven veils on the mechanical performance of carbon fiber/epoxy composites. Compos Struct 194:21-35. https://doi.org/10.1016/j.compstruct.201 8.03.097

[111] Deng M, Dodson C (1994) Paper: an engineered stochastic structure. Tappi Press, Atlanta

[112] van der Heijden S, Daelemans L, De Schoenmaker B et al (2014) Interlaminar toughening of resin transfer moulded glass fibre epoxy laminates by polycaprolactone electrospun nanofibres. Compos Sci Technol 104:66-73. https://d oi.org/10.1016/j.compscitech.2014.09.005

[113] I'Anson SJ, Sampson WW (2007) Competing Weibull and stress-transfer influences on the specific tensile strength of a bonded fibrous network. Compos Sci Technol 67:1650-1658. https://doi.org/10.1016/j.compscitech.2006. 07.002

[114] Eichhorn SJ, Sampson WW (2010) Relationships between specific surface area and pore size in electrospun polymer fibre networks. J R Soc Interface 7:641-649. https://doi. org/10.1098/rsif.2009.0374

[115] Chen G, Zhang J, Liu G et al (2019) Controlling the crack propagation path of the veil interleaved composite by fusion-bonded dots. Polymers (Basel). https://doi.org/10.3 390/polym 11081260

[116] Harik V (2018) Nanotechnology of carbon nanotubes: sensors, transistors and nanocomposites. Mechanics of carbon nanotubes. Academic Press, Cambridge, pp 1-24

[117] Rodríguez-González JA, Rubio-González C (2019) Influence of sprayed multi-walled carbon nanotubes on mode I and mode II interlaminar fracture toughness of carbon fiber/ epoxy composites. Adv Compos Mater 28:19-36. https://d oi.org/10.1080/09243046.2018.1458510

[118] Quan D, Mischo C, Li X et al (2019) Improving the electrical conductivity and fracture toughness of carbon fibre/ epoxy composites by interleaving MWCNT-doped thermoplastic veils. Compos Sci Technol. https://doi.org/10.1 016/j.compscitech.2019.107775

[119] Eskizeybek V, Yar A, Avc1 A (2018) CNT-PAN hybrid nanofibrous mat interleaved carbon/epoxy laminates with improved mode I interlaminar fracture toughness. Compos Sci Technol 157:30-39. https://doi.org/10.1016/j.compscit ech.2018.01.021

[120] Nistal A, Falzon BG, Hawkins SC et al (2019) Enhancing the fracture toughness of hierarchical composites through amino-functionalised carbon nanotube webs. Compos Part B Eng 165:537-544. https://doi.org/10.1016/j.compositesb. 2019.02.001

[121] Hamer S, Leibovich H, Green A et al (2014) Mode I and mode II fracture energy of MWCNT reinforced nanofibrilmats interleaved carbon/epoxy laminates. Compos Sci Technol 90:48-56. https://doi.org/10.1016/j.compscitech.2 013.10 .013

[122] Song Y, Zheng N, Dong X, Gao J (2020) Flexible carboxylated CNT/PA66 nanofibrous mat interleaved carbon fiber/epoxy laminates with improved interlaminar fracture toughness and flexural properties. Ind Eng Chem Res 59:1151-1158. https://doi.org/10.1021/acs.iecr.9b05854

[123] Zheng N, Huang Y, Liu HY et al (2017) Improvement of interlaminar fracture toughness in carbon fiber/epoxy composites with carbon nanotubes/polysulfone interleaves. Compos Sci Technol 140:8-15. https://doi.org/10.1016/j.c ompscitech.2016.12.017

[124] Aly-Hassan MS (2015) A new perspective in multifunctional composite materials. Multifunct Polym Compos Challenges New Solut. https://doi.org/10.1016/B978-0-32 3-26434-1.00002-7

[125] González C, Vilatela JJ, Molina-Aldareguía JM et al (2017) Structural composites for multifunctional applications: 
current challenges and future trends. Prog Mater Sci 89:194-251. https://doi.org/10.1016/j.pmatsci.2017.04.005

[126] Ferreira ADBL, Nóvoa PRO, Marques AT (2016) Multifunctional material systems: a state-of-the-art review. Compos Struct 151:3-35. https://doi.org/10.1016/j.comp struct.2016.01.028

[127] Gagné M, Therriault D (2014) Lightning strike protection of composites. Prog Aerosp Sci 64:1-16. https://doi.org/10. 1016/j.paerosci.2013.07.002

[128] Barjasteh E, Sutanto C, Reddy T, Vinh J (2017) A graphene/graphite-based conductive polyamide 12 interlayer for increasing the fracture toughness and conductivity of carbon-fiber composites. J Compos Mater 51:2879-2887. h ttps://doi.org/10.1177/0021998317705707

[129] Brown SC, Robert C, Koutsos V, Ray D (2020) Methods of modifying through-thickness electrical conductivity of CFRP for use in structural health monitoring, and its effect on mechanical properties - a review. Compos Part A Appl Sci Manuf 133:105885. https://doi.org/10.1016/j.composite sa.2020.105885

[130] Pozegic TR, Hamerton I, Anguita JV et al (2014) Low temperature growth of carbon nanotubes on carbon fibre to create a highly networked fuzzy fibre reinforced composite with superior electrical conductivity. Carbon N Y 74:319-328. https://doi.org/10.1016/j.carbon.2014.03.038

[131] Guo M, Yi X, Liu G, Liu L (2014) Simultaneously increasing the electrical conductivity and fracture toughness of carbon-fiber composites by using silver nanowires-loaded interleaves. Compos Sci Technol 97:27-33. https://doi. org/10.1016/j.compscitech.2014.03.020

[132] Guo M, Yi X, Rudd C, Liu X (2019) Preparation of highly electrically conductive carbon-fiber composites with high interlaminar fracture toughness by using silver-plated interleaves. Compos Sci Technol 176:29-36. https://doi.or g/10.1016/j.compscitech.2019.03.014

[133] Li W, Li Y, Xiang D et al (2019) Simultaneous enhancement of electrical conductivity and interlaminar shear strength of CF/EP composites through MWCNTs doped thermoplastic polyurethane film interleaves. J Appl Polym Sci 136:24-28. https://doi.org/10.1002/app.47988

[134] Wang J, Ma C, Chen G, Dai P (2020) Interlaminar fracture toughness and conductivity of carbon fiber/epoxy resin composite laminate modified by carbon black-loaded polypropylene non-woven fabric interleaves. Compos
Struct 234:111649. https://doi.org/10.1016/j.compstruct.20 19.111649

[135] Burkov M, Eremin A (2018) Hybrid CFRP/SWCNT composites with enhanced electrical conductivity and mechanical properties. J Mater Eng Perform 27:5984-5991. h ttps://doi.org/10.1007/s11665-018-3695-x

[136] Li W, Xiang D, Wang L et al (2018) Simultaneous enhancement of electrical conductivity and interlaminar fracture toughness of carbon fiber/epoxy composites using plasma-treated conductive thermoplastic film interleaves. RSC Adv 8:26910-26921. https://doi.org/10.1039/c8ra 05366a

[137] Chan KY, Jia B, Lin H et al (2018) A critical review on multifunctional composites as structural capacitors for energy storage. Compos Struct. https://doi.org/10.1016/j.c ompstruct.2017.12.072

[138] Luo X, Chung DDL (2001) Carbon-fiber/polymer-matrix composites as capacitors. Compos Sci Technol 61:885-888. https://doi.org/10.1016/S0266-3538(00)0016 6-4

[139] Xu Y, Lu W, Xu G, Chou TW (2021) Structural supercapacitor composites: a review. Compos Sci Technol 204:108636. https://doi.org/10.1016/j.compscitech.2020. 108636

[140] Senokos E, Ou Y, Torres JJ et al (2018) Energy storage in structural composites by introducing CNT fiber/polymer electrolyte interleaves. Sci Rep 8:1-10. https://doi.org/10. 1038/s41598-018-21829-5

[141] Sun J, Gargitter V, Pei S et al (2020) Mechanical and electrochemical performance of hybrid laminated structural composites with carbon fiber/solid electrolyte supercapacitor interleaves. Compos Sci Technol 196:108234. https://d oi.org/10.1016/j.compscitech.2020.108234

[142] TFP Ltd. James Cropper PLC (2021) Fracture toughness. h ttps://www.tfpglobal.com/products/composite-materials/fra cture-toughness. Accessed 1 Mar 2021

[143] Cytec Industries Inc. (2019) Patent TWI677424B: composite materials with high $\mathrm{z}$-direction electrical conductivity and methods of fabricating a composite. https://patents.g oogle.com/patent/TWI677424B/en

Publisher's Note Springer Nature remains neutral with regard to jurisdictional claims in published maps and institutional affiliations. 